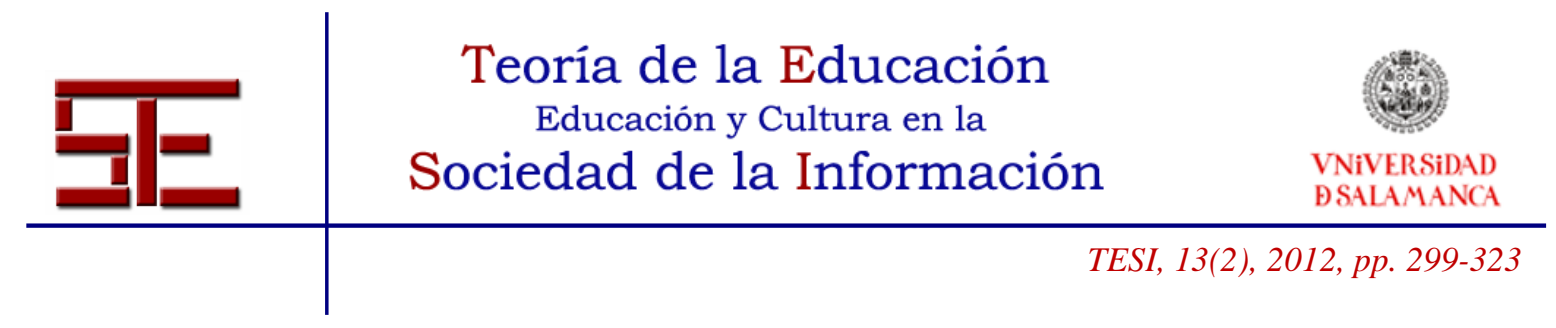

\title{
AUTONOMÍA Y RESPONSABILIDAD COMO VALORES CLAVE PARA LA ELABORACIÓN DE NORMAS DE CONVIVENCIA EN LA ESO
}

Resumen: Algunas de las cuestiones que se plantean en el artículo son las siguientes: ¿Son los alumnos capaces de organizar el comportamiento y la convivencia en el aula? ¿Están capacitados para elaborar sus propias normas? o ¿Solamente se trata de un planteamiento teórico que resulta inviable de llevar a la práctica? En todo caso, ¿qué nivel de responsabilidad y autonomía pueden asumir en el funcionamiento del aula?

El aprendizaje de normas en el aula constituye una experiencia real, muy próxima a la experiencia y los intereses de los alumnos, que permite trabajar valores como la responsabilidad, el respeto, la participación, el diálogo y la democracia. A su vez les enseña a participar en asambleas de aula, a trabajar en pequeños grupos, a formular propuestas y a llegar al consenso a través del diálogo y la negociación.

La investigación experimental en este campo ha demostrado en múltiples ocasiones que cuando el docente genera oportunidades de reflexión sobre la convivencia en el aula e involucra a sus alumnos en la misma, se produce una clara tendencia a la disminución de las conductas disruptivas.

Palabras clave: valores; normas; diálogo; participación; convivencia.

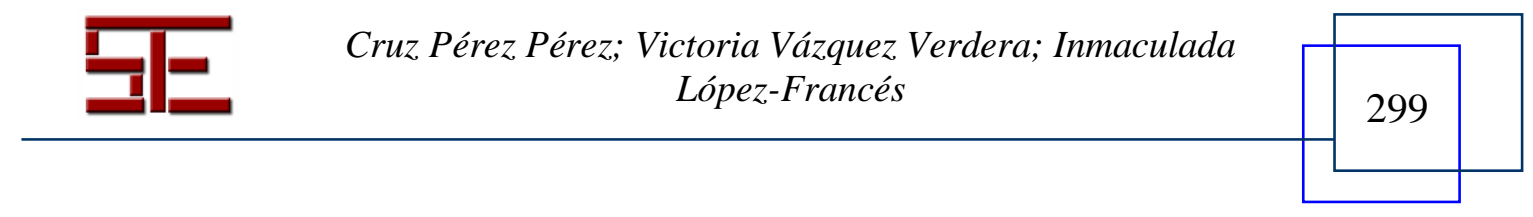




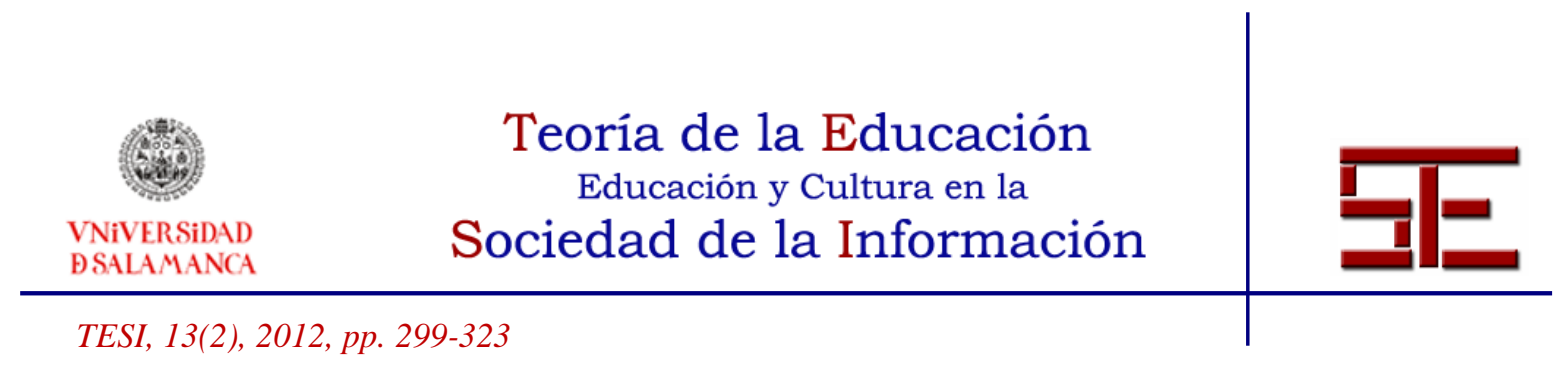

\section{AUTONOMY AND RESPONSIBILITY AS KEY VALUES FOR THE ELABORATION OF RULES OF COEXISTENCE IN THE ESO}

Abstract: Some of the themes set out in the article are the following: are pupils capable of organising behaviour and coexistence in the classroom? Are they able to elaborate their own rules? Or is it only a theoretical approach that is unviable to put into practise? In any case, what level of responsibility and autonomy are they able to assume in the functioning of the classroom?

The learning of rules in the classroom constitutes a real experience, very close to the experience and the interests of the pupils, that permits them to work on values such as: responsibility, respect, participation, dialogue and democracy. At the same time, it teaches them to participate in class meetings, work in small groups, formulate proposals and arrive to a consensus through dialogue and negotiation.

The experimental research in this field has demonstrated on numerous occasions that when the teacher generates opportunities to reflect on coexistence in the classroom and involve their pupils, it produces a clear tendency to decrease disruptive behaviour.

Key words: values; rules; dialogue; participation; coexistence.

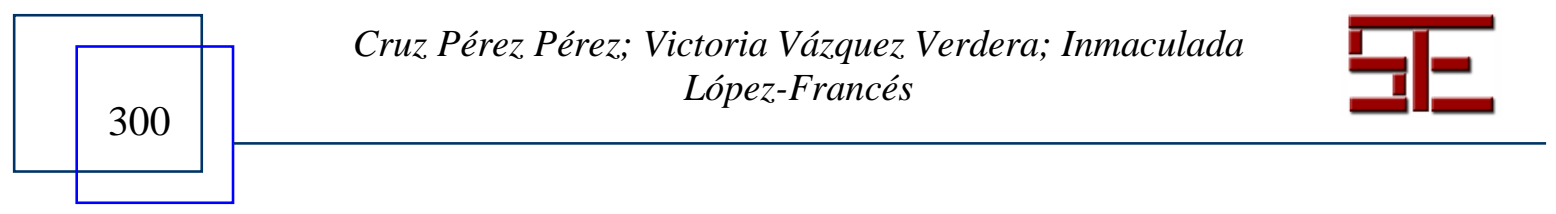




\begin{tabular}{c|c} 
Teoria de la Educación \\
Educación y Cultura en la \\
Sociedad de la Información
\end{tabular}

\section{AUTONOMÍA Y RESPONSABILIDAD COMO VALORES CLAVE PARA LA ELABORACIÓN DE NORMAS DE CONVIVENCIA EN LA ESO}

Fecha de recepción: 20/09/2011; fecha de aceptación: 20/10/2011; fecha de publicación: 26/07/2012

Cruz Pérez Pérez

cruz.perez@uv.es

Universidad de Valencia

Victoria Vázquez Verdera,

Toya.vazquez@uv.es

Universidad de Valencia

Inmaculada López-Francés

Inmaculada.1opez-frances@uv.es

Universidad de Valencia

\section{1. - INTRODUCCIÓN}

La nueva concepción de la educación que se ha ido abriendo paso en las últimas décadas, pone el acento en un tipo de contenidos de carácter más formativo, como el aprendizaje de pautas de convivencia, normas, valores, actitudes, creencias, el desarrollo de la capacidad de juicio, de la capacidad crítica, el autocontrol, la educación emocional. En esta línea, entendemos que el aprendizaje de valores como de la autonomía y la responsabilidad permite a los jóvenes ${ }^{1}$ integrarse responsablemente en esta nueva sociedad y responder a los retos que los profundos cambios sociales están planteando. La experiencia de la convivencia cotidiana que se realiza en los centros escolares constituye un marco idóneo para aprender estos valores.

De cualquier manera, es necesario tener en cuenta que vivimos en una sociedad muy individualista donde los valores morales como la autonomía y la responsabilidad, en general, son aceptados como principios estructurantes de la vida común, pero que

\footnotetext{
${ }^{1}$ Nota: utilizaremos indistintamente el término neutro para referirnos a hombres y mujeres con el fin de facilitar la lectura del lector o lectora.
}

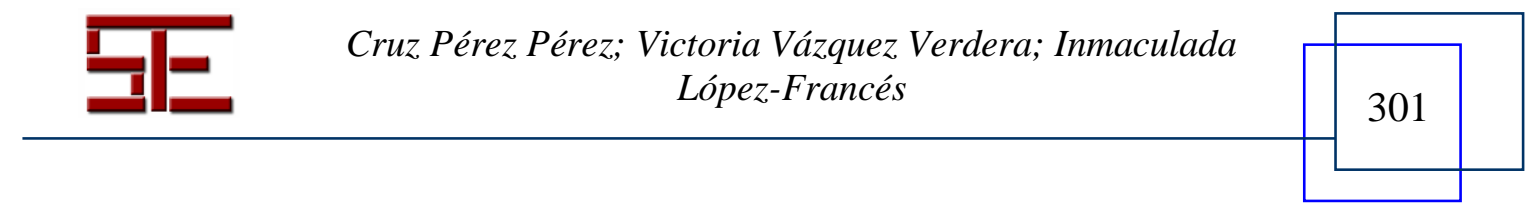




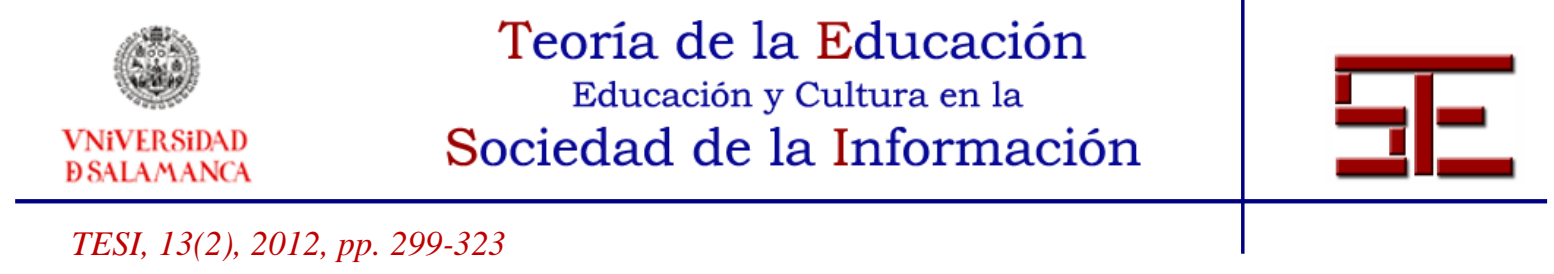

motivan poco hacia la acción. Son valores demasiado abstractos que es preciso llenar de contenidos más precisos. El predominio de los llamados valores de la postmodernidad es cada vez más evidente: estética, placer, vivir el presente, éxito, dinero, etc. Son valores que proporcionan una gratificación inmediata al individuo de un modo tangible, al contrario de los valores morales o éticos, caracterizados por exigir un gran esfuerzo y sacrificio, sin aportar a la persona una gratificación inmediata. Por ello, trabajar en esta línea requiere una preparación específica del profesorado y unas estrategias claras de intervención con objetivos a medio y largo plazo.

\section{2.- AUTONOMÍA Y RESPONSABILIDAD EN EL CONTEXTO DE LA EDUCACIÓN EN VALORES}

Existen diversas teorías sobre la educación en valores: Teorías sociologistas, la Educación del Carácter, Filosofía para niños, Desarrollo del Juicio Moral, Clarificación de Valores, Construcción de la Personalidad Moral. De cada una de ellas se deriva un modelo de intervención práctica, y ello inevitablemente nos lleva a plantearnos la siguiente cuestión: ¿Desde qué perspectiva o enfoque teórico es conveniente abordar la educación en valores?

Para abordar esta cuestión debemos tener en cuenta que la persona es un ser cognitivoracional, afectivo, emocional y volitivo-conductual (Zubiri, 1992). Estos tres aspectos deben ser necesariamente integrados en una teoría general sobre educación y, en especial, en una teoría sobre educación en valores. Por lo tanto se vislumbra completamente necesaria la apuesta por un modelo comprensivo, global e integrador de las diversas perspectivas existentes sobre educación en valores (filosóficas, socioantropológicas, psicosociológicas). Aunque el profesorado o el centro en su conjunto no coincidan en aspectos importantes de muchas teorías sobre el modelo que proponen de construcción de la persona, no pueden permitirse el lujo de centrarse en una sola y prescindir de las aportaciones de las demás. La concepción constructivista del aprendizaje en la que se sitúa el marco educativo actual no siempre es la más adecuada para explicar el aprendizaje de valores. Por ello, es importante tener en cuenta las aportaciones de otras escuelas, perspectivas o líneas de pensamiento. El profesor debe ser capaz de integrar diferentes perspectivas, en un modelo global, comprensivo e integrador, que aproveche las potencialidades de cada una de ellas para el logro de un objetivo que difícilmente se podría alcanzar desde posiciones reduccionistas: conseguir que la persona esté en condiciones de apreciar los valores y de construirse a sí misma social y axiológicamente (Martínez, 1998).

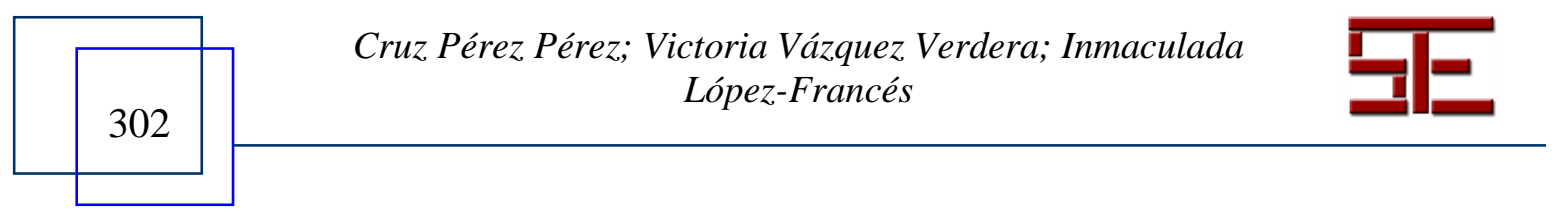




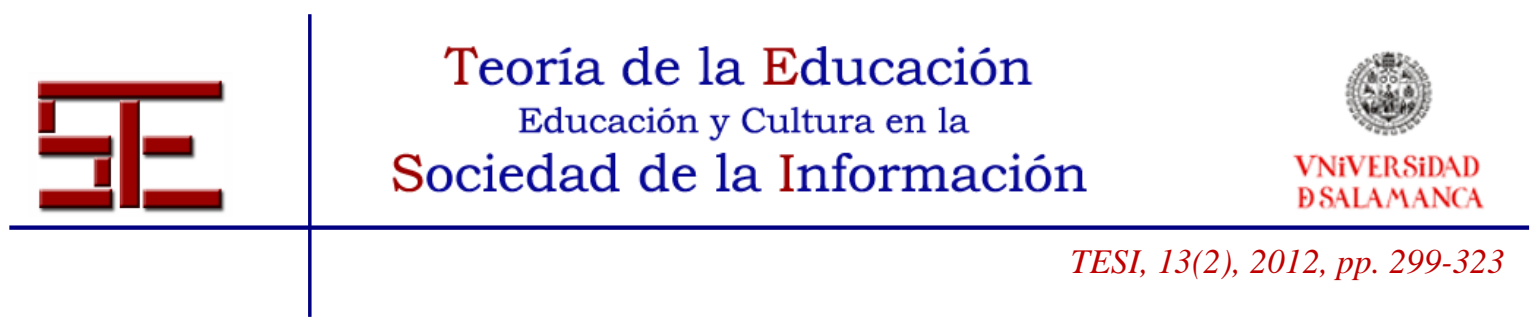

La experiencia cotidiana del valor es fundamental para que los alumnos se apropien del mismo. Ahora bien, la experiencia del valor será siempre contradictoria, en el sentido de que la existencia de valores y contravalores obliga a una opción/elección en el educando. Las propuestas artificiales, descontextualizadas del valor, frecuentes en la pedagogía tradicional, difícilmente superan el ámbito de la noción o del concepto, careciendo, por tanto, de la fuerza emotiva necesaria para mover al sujeto a la apropiación del valor (Ortega, Mínguez y Gil, 1996).

El profesorado no puede dejar la educación de un tema tan importante como los valores a las fuerzas del azar, sino que, de una manera intencionada y razonablemente fundada, debe elaborar proyectos y programas concretos de intervención para educar en los valores que, de un modo consensuado, se hayan establecido en el PEC con la colaboración de todos los miembros de la comunidad educativa. Para ello debe conocer las técnicas y los procedimientos pedagógicos que han sido probados con éxito, y entre los que cabría destacar las técnicas de clarificación de valores, el desarrollo del juicio moral, el desarrollo de la perspectiva social y la empatía, las técnicas de cooperación, la comunicación persuasiva, la presentación de modelos valiosos y las técnicas de autorregulación del comportamiento.

Para educar en valores en una sociedad plural, en primer lugar es necesario enseñar a los sujetos a captar los valores. Tal y como señala la profesora Adela Cortina, la captación del valor no es cuestión únicamente de intuición personal, sino de preparación. Difícilmente podemos captar los valores de una obra literaria o pictórica si no estamos preparados para ello. Por lo tanto, es necesario cultivar las predisposiciones necesarias para poder apreciar los valores (Cortina, 1996).

En la misma línea, el profesor Miquel Martínez señala la necesidad de crear las condiciones necesarias para que el alumno aprenda a valorar como tales determinados valores, pero también para que aprenda a rechazar los contravalores y para que sea capaz de construir su propia matriz de valores ante cuestiones socialmente comprometidas como las que se presentan en cualquier sociedad plural. Se trata de que el sujeto establezca su propia jerarquía de valores y sea capaz de interpretarlos en función del contexto sociocultural o personal en el que se encuentre (Martínez, 1998). Para lograr estos objetivos, es necesario crear unas condiciones sociales que ofrezcan buenas oportunidades prácticas para educar en esta línea, las cuales se concretarían de la siguiente forma:

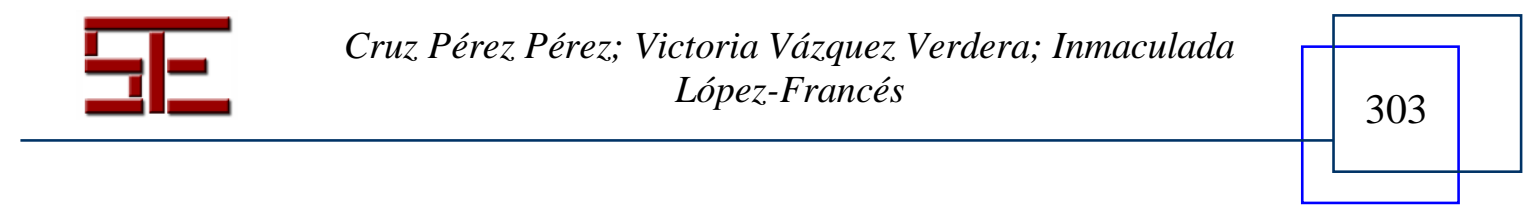




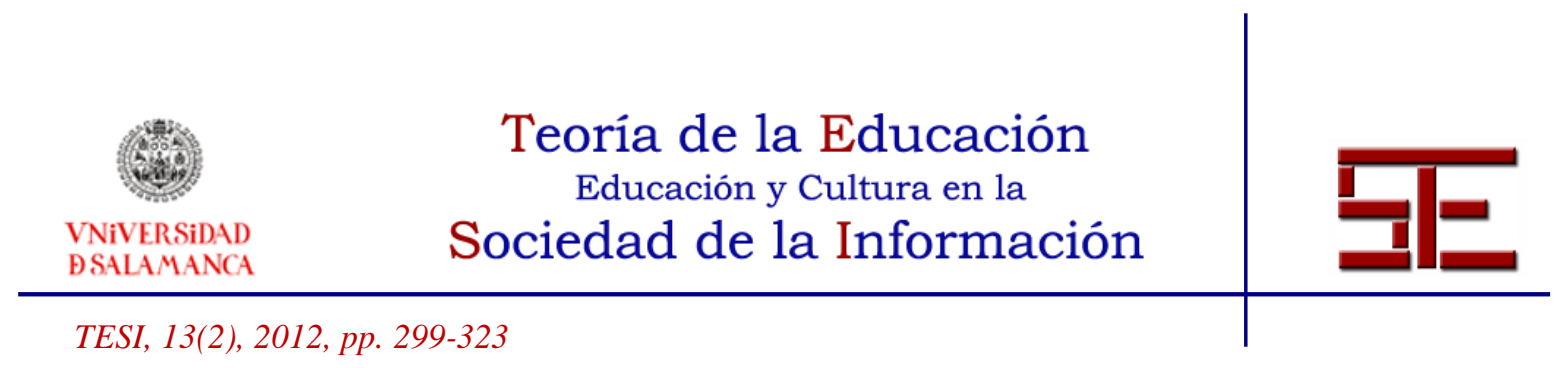

- Prácticas que permitan apreciar y estimar como valiosa la convivencia en sociedades plurales y heterogéneas.

- Favorecer la implicación en proyectos colectivos.

- Apostar por un modelo de sociedad basada en la inclusión.

- Proponer un modelo de vida que propicie una ciudadanía activa.

- Asumir las responsabilidades que a cada uno le corresponden como ciudadano, respondiendo de las acciones y de las consecuencias de éstas.

\section{3.- ¿CÓMO ABORDAR LA ENSEÑANZA DE LA AUTONOMÍA Y LA RESPONSABILIDAD?}

En el presente trabajo abordamos el tema de la educación en la autonomía y la responsabilidad del alumnado de la ESO, utilizando la estrategia básica de implicar al mismo en la elaboración y puesta en práctica de un conjunto de normas de comportamiento y convivencia para el contexto escolar. Se trata de lograr aprendizajes profundos y duraderos que obliguen a los alumnos a ejercer su responsabilidad y les conduzcan a la autonomía moral. Esta formación la consideramos básica para vivir y desenvolverse en el mundo actual que cada vez es más plural y diverso, y en el que es necesario aprender a convivir pacíficamente, compartiendo proyectos comunes con otras personas, respetando las diferencias y los derechos de los demás y cumpliendo las normas fundamentales que nos damos entre todos.

Pero ¿cómo enseñar a los alumnos a ser responsables, a ser justos, a desarrollar el sentido crítico, a respetar a las personas, a ser democráticos, a ser autónomos? Son contenidos que no se pueden enseñar exclusivamente con una metodología tradicional en la que el profesor explica cada uno de estos conceptos y cómo hay que actuar de acuerdo con los mismos. Ello solamente constituye una primera fase del proceso educativo, que es necesario complementar con una enseñanza vivenciada, experiencial, creando el clima de aula y centro adecuado para que los alumnos puedan experimentar y sentir por sí mismos aquellas situaciones que les permitan avanzar en la construcción de su personalidad.

Las técnicas y estrategias que se proponen en este trabajo para conseguir estos objetivos consisten en facilitar el autogobierno de los alumnos, de forma que ellos mismos elaboren sus normas por procedimientos democráticos, y participen en la autodirección en la vida colectiva colaborando en la toma de decisiones. Estos cambios deben permitir

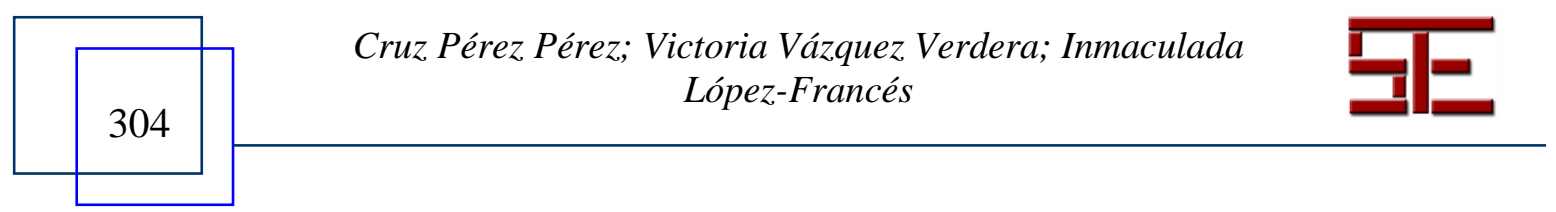




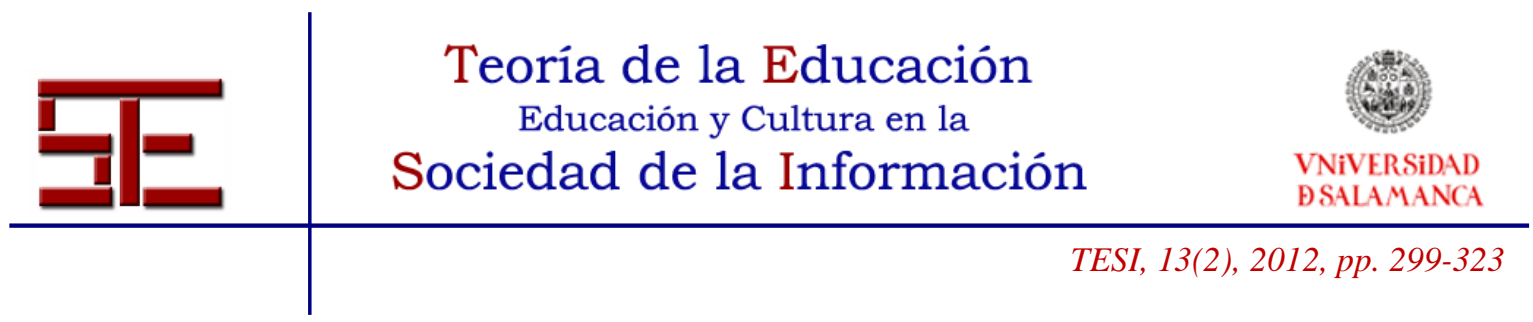

la creación de un "clima de aula" en el que se traten abiertamente todos los temas que afecten a profesores y alumnos -normas de convivencia, conflictos ordinarios, organización del aula, etc.-, se favorezca el consenso en los temas controvertidos y todos puedan expresar libremente sus ideas y opiniones.

Los efectos a medio plazo de la aplicación de estrategias y técnicas de aprendizaje de valores y normas democráticas, según se demuestra en las investigaciones realizadas en los últimos años (Pérez, 96; Escámez y Pérez, 98; Pérez y Asensi, 2000; Pérez y Llopis, 2003, Pérez, 2009, Pérez y López, 2010) son la formación de grupos-clase más cohesionados, con mayor nivel de autonomía sociomoral, en el que los alumnos, independientemente de sus metas individuales, trabajan y luchan por unas metas colectivas que les hacen más solidarios. Ello se traduce en que no dependen de la rigidez del profesor o la profesora para mantener el comportamiento adecuado a las normas establecidas, asumen los problemas individuales como propios del grupo, se implican en la organización de la vida colectiva, son capaces de afrontar los conflictos por ellos mismos sin requerir la ayuda constante del profesorado, tienen un mayor sentido crítico, son más respetuosos. Una diferencia significativa entre este grupo-clase y otro educado a la manera y usanza tradicional, empleando métodos más rígidos y autoritarios, es que el primero mantiene unas pautas de conducta más constantes, independientemente del profesor o del contexto en el que se encuentren y, por el contrario, los segundos tienden a aumentar los comportamientos disruptivos cuando se encuentren en contextos menos controlados (con profesores menos experimentados, en el patio, en actividades complementarias, etc.).

También entendemos que estas estrategias de carácter participativo son fundamentales a nivel social, pues hay que tener en cuenta que la escuela y el instituto son uno de los contextos más importantes de socialización de los alumnos y es el vivero de ideas y percepciones acerca de principios tan importantes como la democracia y la justicia.

\section{4.- LA ELABORACIÓN DE LAS NORMAS DEL AULA COMO ESTRATEGIA DE INTERVENCIÓN EDUCATIVA}

Partimos de un concepto positivo de las normas que las entiende no como reglas mantenidas exclusivamente por el ejercicio de la coacción, sino como reglas que son fruto de un consenso social y que son cumplidas voluntariamente por la mayoría de la población, al considerarlas válidas y necesarias para la convivencia del grupo. Este sentimiento de validez es el que dota a las normas de fuerza de obligación. Así, por

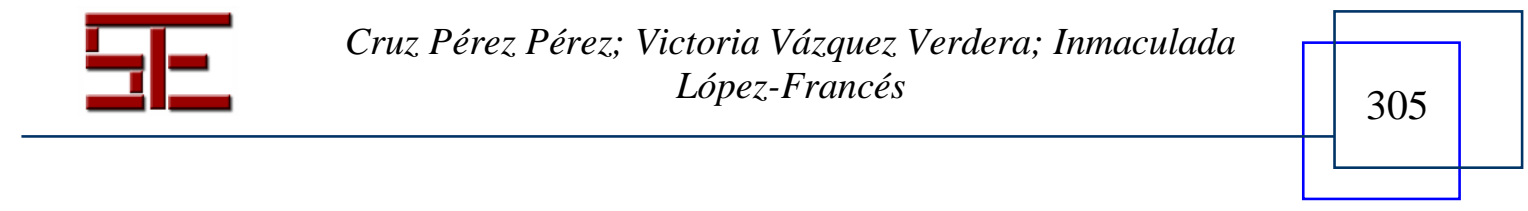




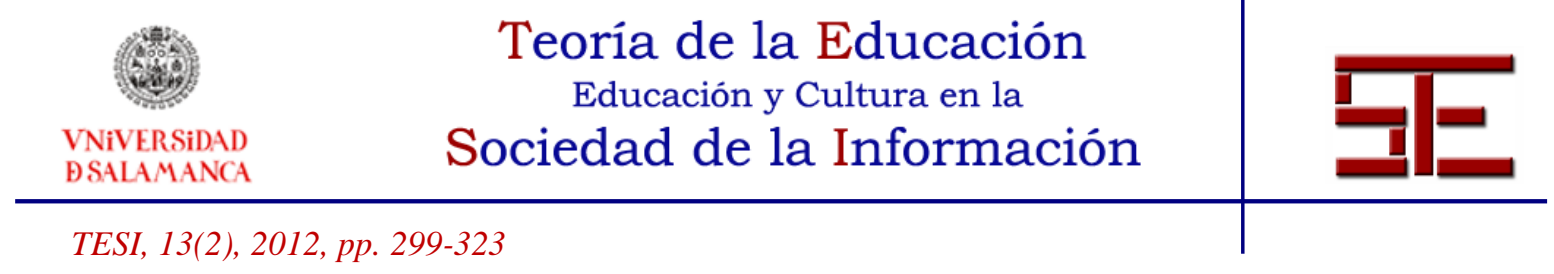

ejemplo, la mayor parte de las personas acatamos la norma de que no se puede causar daño físico a los demás, porque deriva de un valor compartido como es el respeto a la persona y a sus derechos fundamentarles. Entendemos que es una norma ética necesaria y básica para la convivencia en sociedad y, aunque no existiesen sanciones, la mayor parte de los miembros del grupo social cumplirían dicha norma por la bondad intrínseca de la misma. Pero es necesaria la existencia de sanciones asociadas a su incumplimiento, porque siempre existe una parte del grupo social que necesita de esta coacción para cumplirla, y porque debe existir una penalización para los que la transgreden.

En conclusión, podemos decir que las normas son prescipciones, basadas en un conjunto de valores consensuados socialmente, que sirven para regular la conducta de las personas y que permiten realizar juicios evaluativos sobre la bondad o maldad de las acciones. Suelen tener un carácter coactivo o impositivo (imposición exterior basada en la fuerza o poder), que se pierde cuando se llega a asumir el valor que la fundamenta, para convertirse en una aceptación interior y libre (Pérez, 2009).

\section{1.- Importancia del aprendizaje de normas en el contexto escolar}

Durante las últimas décadas, la legislación educativa de todos los países desarrollados ha establecido la relevancia de los contenidos actitudinales para la formación integral de la persona. Las normas, como plasmación de los valores, forman parte de estos contenidos actitudinales y constituyen un elemento educativo esencial que condiciona claramente el "modo de ser" del sujeto, entendido éste como una predisposición característica y personal para enfrentarse a las diversas situaciones que se plantean en la vida. Los valores y las normas que un individuo ha asumido como propios le confieren cierta unidad y coherencia en la manera de sentir, enjuiciar y actuar.

El tema de las normas de comportamiento y convivencia suele ser prioritario para los centros escolares, generando un permanente debate y preocupación. El profesorado dedica mucho esfuerzo y una gran cantidad de tiempo para establecer un conjunto de normas, darlas a conocer al alumnado y conseguir que se cumplan. Sin embargo es frecuente el uso de técnicas poco adecuadas para alcanzar estos objetivos, lo cual genera unos pobres resultados que terminan desmotivando y agotando al profesorado. En clases con alumnos "conflictivos", los problemas de comportamiento de los mismos centran la atención del profesor de tal manera que le dejan muy poco margen para otras tareas educativas. Tanto es así que, en la mayor parte de las encuestas realizadas, el

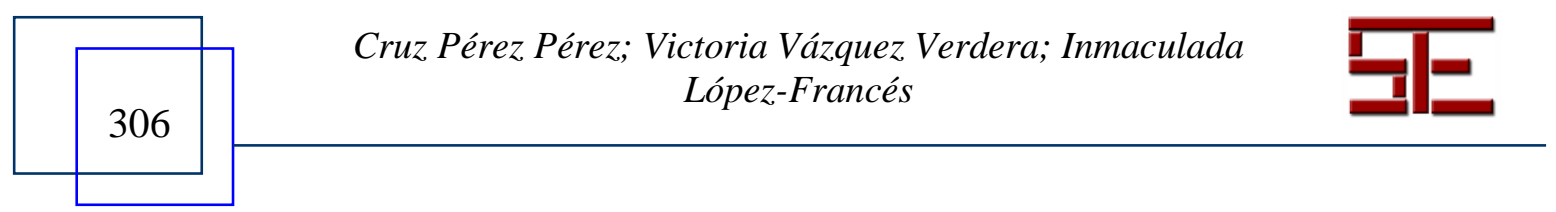




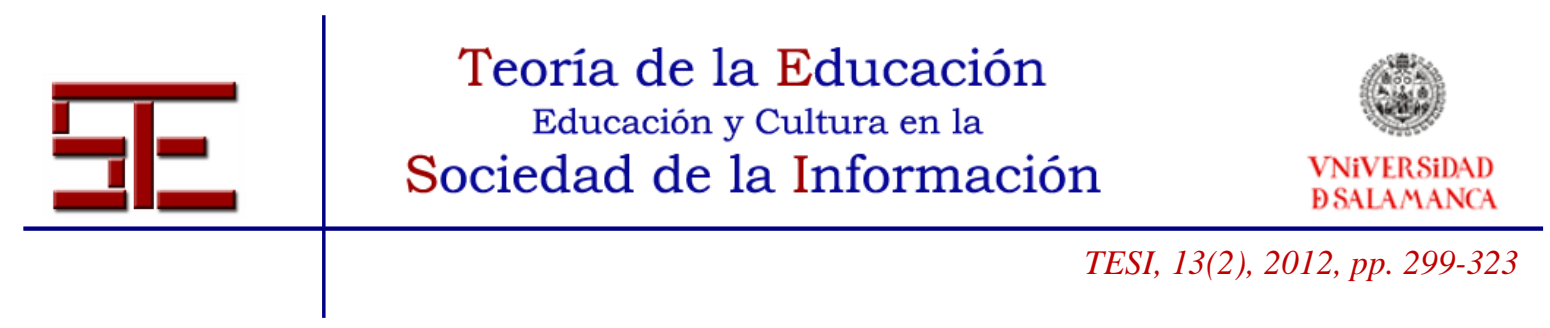

profesorado entiende que la conducta disruptiva de los alumnos es uno de los aspectos que más les preocupa a nivel personal y profesional. Esta preocupación llega hasta el punto de que en algunos centros con problemas graves en el comportamiento del alumnado, especialmente de ESO, el profesorado se limita a "aguantar" como puede sus cuatro o cinco sesiones de clase con sus alumnos, esperando que acabe el día, el trimestre, el curso y lo que falte hasta poder pedir el ansiado traslado, en el caso de que desarrolle su docencia en un centro público. Esta situación supone una total desmotivación y falta de alicientes inmediatos, que en muchos casos se prolonga al comprobar que el nuevo centro tiene unos problemas similares al de procedencia.

Es evidente que la existencia de un conjunto de normas bien organizado y estructurado repercute de manera directa en la "calidad de vida" del profesorado, que encuentra más alicientes para desarrollar su labor profesional. Ello siempre supone un esfuerzo inicial importante hasta llegar a organizar un sistema de normas y consecuencias válido para un curso, un ciclo, una etapa o todo el centro, pero tiene unos efectos claros en la educación de los alumnos y, por lo tanto, en el "clima educativo" del centro. Ya no se trata de "aguantar" las horas de permanencia en el centro esperando tiempos mejores, sino que existe un horizonte educativo, con sus bondades y sus conflictos, que da sentido al trabajo realizado.

Los centros escolares constituyen un marco normativo privilegiado, pues en los mismos la existencia de un conjunto de normas bien organizado permite regular la conducta de las personas, hace previsibles las relaciones humanas y contribuye a la formación de la personalidad de los sujetos. Es importante que tanto alumnado como profesorado del centro asuman las normas y reglas que entre todos se han dado, y que tomen conciencia de que el grupo y la institución a la que pertenecen, esperan de ellos una serie de comportamientos adecuados a los valores que inspiran el proyecto educativo.

\section{2.- ¿Cómo se aprenden las normas?}

El hombre, como ser social que es, pasa una parte importante de su vida aprendiendo normas, ya sea de forma consciente o inconsciente. Aprendemos normas lingüísticas, de circulación, afectivas, morales, gestuales, cognitivas, de urbanidad, de supervivencia, etc. Pero ¿cómo se aprenden las normas? ¿Existen algunas claves que faciliten estos aprendizajes?

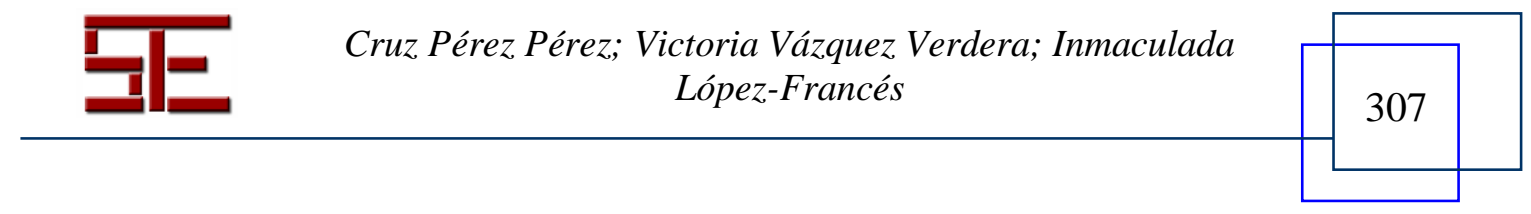




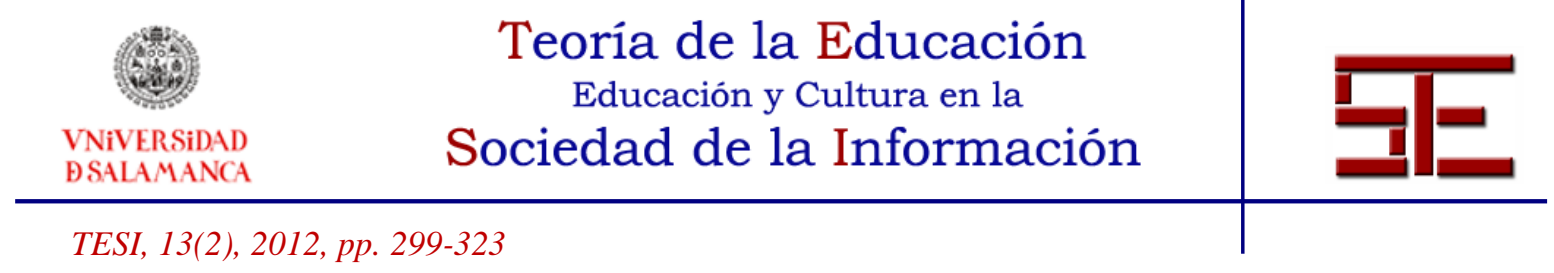

Comenzaremos por señalar que, como en otros muchos contenidos educativos, el aprendizaje de normas tiene una vertiente teórica y otra práctica, las cuales en la mayor parte de los casos son complementarias.

\section{a) Aprendizaje práctico de las normas}

Las personas se tienen que enfrentar continuamente a situaciones nuevas, lo cual les obliga a aprender multitud de normas. Puesto que no es posible ni recomendable explicitarlas todas, las normas se van aprendiendo poco a poco por la experiencia.

La mayor parte de las normas se aprenden de un modo no consciente en las diversas situaciones que se dan en la vida diaria. Es un proceso de inmersión en el que el sujeto se tiene que enfrentar a las situaciones cotidianas que están reguladas por normas implícitas o explícitas. El sujeto se adapta a las nuevas situaciones y aprende las normas mediante su uso y su participación en el grupo social. A esta tarea no se suele dedicar un espacio y un tiempo determinado, sino que se aprenden en ese proceso de interacción social.

La inmersión en la nueva realidad supone enfrentarse a un conjunto de estímulos e información que se debe decodificar, relacionar con lo ya conocido e integrar en el sistema cognitivo. Así, por ejemplo, cuando un alumno llega nuevo a un centro escolar, existen un elevado número de normas y rutinas que debe aprender. Se le pueden explicar las normas fundamentales del centro como las referidas a los horarios, trabajos, disciplina, etc., pero sería contraproducente establecer una interminable lista de normas referidas a situaciones particulares. Éstas las irá aprendiendo poco a poco con su uso.

\section{b) Aprendizaje teórico de las normas}

En muchos contextos e instituciones, entre las que se encuentran las escolares, existen una serie de normas explícitas cuyo cumplimento es necesario para el funcionamiento del sistema. El conocimiento de estas normas básicas se suele trabajar previamente de un modo teórico con el objetivo de que los alumnos descubran su existencia y significado, y para que tomen conciencia de la importancia de las mismas para la convivencia. La comprensión de las normas se espera que facilite su cumplimiento.

Aunque conocer una norma no garantiza su cumplimiento, esta modalidad educativa es perfectamente válida y necesaria, pues establece una serie de regularidades en la vida

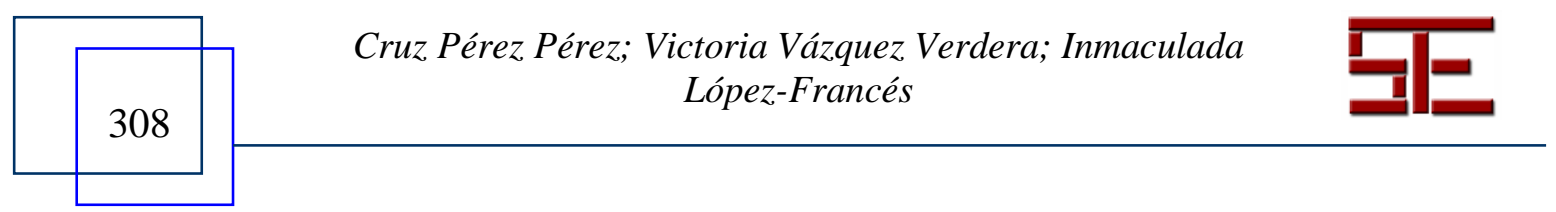




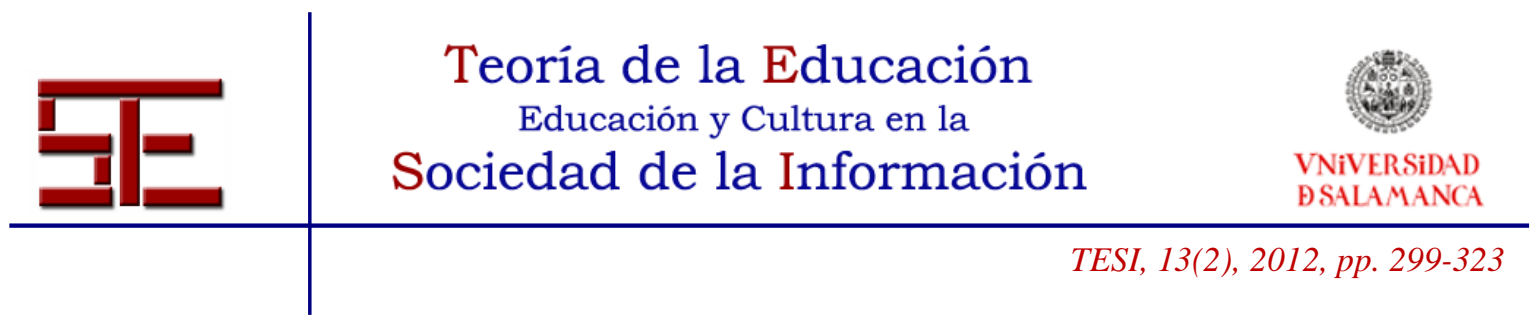

social que da seguridad a los alumnos y les permite establecer el comportamiento que se espera de ellos. La formulación de normas establece un nivel moral que es independiente de su realización concreta, es decir, que constituye un horizonte de valor que se encuentra a salvo de las múltiples transgresiones que se suelen producir en la aplicación de las normas. También sirve como referencia para la evaluación de las conductas concretas.

También es necesario trabajar las normas de modo teórico ante situaciones que, por su peligrosidad o novedad, no permiten un aprendizaje práctico por ensayo y error. Así, por ejemplo, un profesor que va por primera vez al laboratorio de química con sus alumnos, no puede arriesgarse a que éstos sufran un accidente mientras aprenden las normas de uso de los productos químicos existentes. Deberá explicar y razonar la existencia de unas normas para trabajar y manipular estos productos. No puede recorrer el proceso de aprendizaje de estas normas de un modo práctico probando un comportamiento, analizando las consecuencias del mismo, reconociendo los errores y volviendo a intentarlo.

¿Cómo se relacionan ambos procesos de aprendizaje de normas? En principio decir que funcionan con una autonomía relativa, pues unas normas se prestan más al aprendizaje teórico y otras al práctico. Pero de poco serviría conocer una norma si no se llega a poner en práctica y viceversa, pues es casi imposible formular una norma si antes no se han dado situaciones prácticas que hagan necesaria su existencia. Es decir, que existe una relación inequívoca entre ambos procesos, pues la experiencia que proporciona el uso de una norma es necesaria para activar el proceso de toma de conciencia de la misma, pero, a su vez, la toma de conciencia facilita la comprensión de las normas, de las situaciones donde se aplican y de cómo se las usa. Esta mejor comprensión de la norma reduce las dificultades que se plantean en la puesta en práctica de la misma.

\section{3.- Dificultades que plantea el aprendizaje de normas}

El aprendizaje de normas en el aula presenta una serie de dificultades que es necesario tener en cuenta en toda intervención educativa. Estas dificultades serían las siguientes:

a) Intervenciones puntuales ante el comportamiento disruptivo. El aprendizaje de normas no se suele abordar utilizando programas globales de carácter preventivo. Lo más frecuente es que el profesorado no se plantee de un modo serio el problema del comportamiento de los alumnos, hasta que se producen

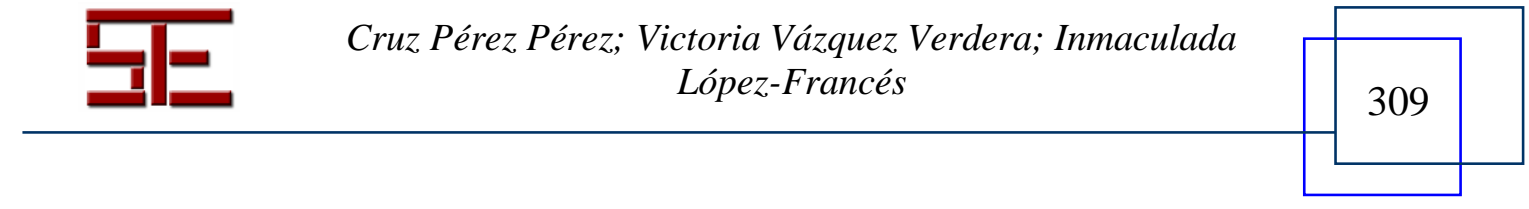




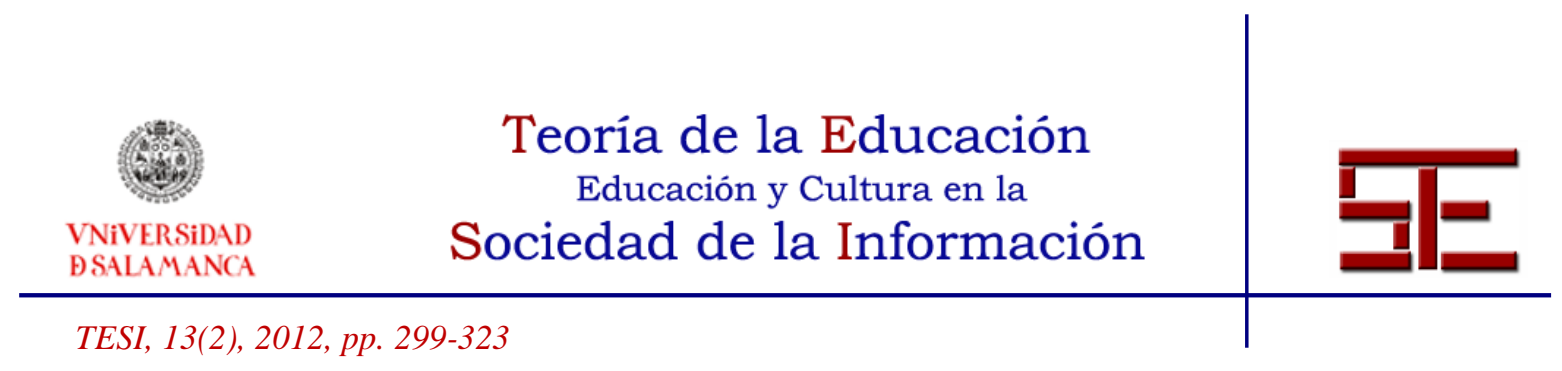

situaciones conflictivas graves. En estos casos, se suele afrontar la situación utilizando técnicas de modificación de conducta de tipo conductista (uso de reforzadores positivos, negativos o materiales, coste de respuesta, tiempo fuera, extinción, saciación, etc.), las cuales no siempre tienen la pervivencia necesaria en el tiempo para producir los efectos deseados. En el mejor de los casos cuando se aplican con éxito y solucionan el problema surgido no consolidan un modelo sistemático de intervención y, por lo tanto, son unas técnicas poco útiles desde el punto de vista de la formación de los alumnos, si entendemos ésta como asimilación gradual y voluntaria de un conjunto de normas de comportamiento y convivencia.

b) Falta de coordinación del profesorado en el establecimiento de normas. La existencia de un conjunto de normas consolidadas mejora de modo notable el bienestar del profesorado, pero ello requiere de elevados niveles de coordinación, especialmente en E. Secundaria. Si tenemos en cuenta la tradición del profesorado de trabajar de modo individual y las dificultades que surgen a la hora de planificar acciones coordinadas o intervenciones de todo el equipo, comprenderemos lo complejo de este modelo de intervención. Es una práctica bastante habitual que cada profesor tenga "sus" propias normas, y que los alumnos se adapten a las mismas, es decir, que en vez de haber unas normas de la clase o del curso, hay unas normas de tal o cual profesor, el cual las impone y exige su cumplimiento en su clase. En otras ocasiones sí que se establece un conjunto de normas de modo coordinado entre el profesorado, pero los criterios de aplicación pueden ser tan dispares que de hecho una misma norma se puede convertir en algo muy diferente dependiendo del profesor que intervenga. Estas situaciones multiplican el número de normas y desorientan en gran medida a los alumnos, que no tienen unos patrones claros de referencia.

c) Tendencia a imponer las normas a los alumnos. Lo más frecuente es que las normas de comportamiento y las sanciones asociadas, se impongan a los alumnos sin darles la oportunidad de analizarlas y debatirlas y, por lo tanto, despreciando el enorme potencial educativo que encierran. Ello hace que los alumnos vean las normas como un instrumento del profesorado para controlar su comportamiento, más que como un elemento que facilita la convivencia. Por lo tanto, cuando no existe el control adecuado por parte del profesorado, los alumnos transgreden las normas y no las llegan a asimilar como propias, al no sentir la necesidad de las mismas. Por el contrario, cuando las normas son

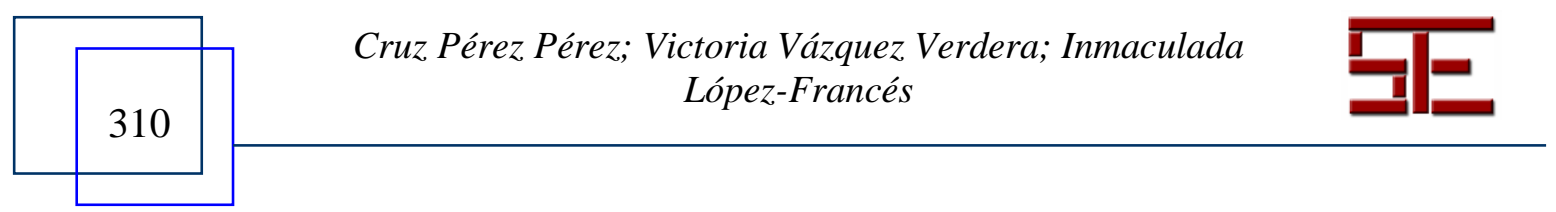




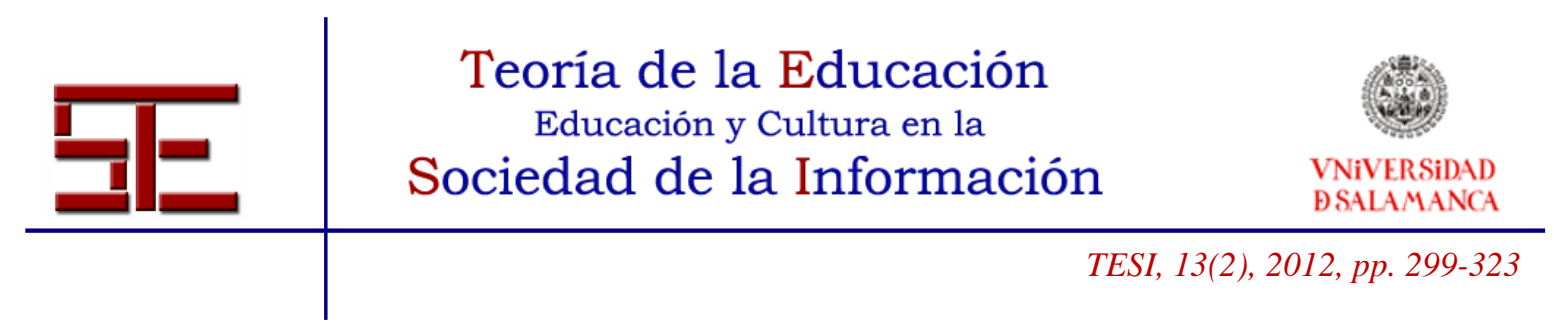

entendidas como necesarias por los alumnos, y se les da la oportunidad de participar en la elaboración y selección de las mismas, adquieren una fuerza moral que facilita su cumplimiento y asimilación de forma duradera. Pero ello requiere procesos educativos largos y complejos en los que los alumnos deben evolucionar desde una moral heterónoma a una moral autónoma.

d) La gran movilidad existente entre el profesorado. Especialmente en la enseñanza pública, por determinadas circunstancias, se da una gran movilidad del profesorado, lo cual es una dificultad añadida para elaborar y consolidar sistemas de normas. El origen de este problema no está en los concursos de traslados del profesorado definitivo, el cual es beneficioso pedagógicamente, en la medida que permite el intercambio entre centros de diversos profesores con distinta formación, puntos de vista, experiencias, etc. en un ciclo razonable, sino en la gran bolsa de profesorado interino existente que cambia de centro cada año, o incluso cada mes, ante la falta de criterios o normas que faciliten su continuidad en el mismo puesto de trabajo. Esta disponibilidad del profesorado facilita la tarea administrativa, pero a nivel pedagógico constituye un gran problema en la medida que dificulta la consolidación de equipos estables de profesorado que puedan desarrollar proyectos a medio o largo plazo. Y el aprendizaje de normas requiere de estos plazos al objeto de que los alumnos interioricen unos patrones específicos de conducta. Cuando no existe una estabilidad entre el profesorado, es difícil llevar adelante proyectos educativos concretos adaptados al entorno o establecer unos patrones específicos de comportamiento, lo cual desorienta a los alumnos y redunda en un incremento de los comportamientos disruptivos.

\subsection{Modelos de intervención en el aprendizaje de normas: reactivos/preventivos}

Si analizamos las actitudes del profesorado ante el comportamiento de los alumnos en el aula, podemos diferenciar dos grandes tendencias o modelos de intervención que van a condicionar claramente lo que es el clima del aula y el desarrollo moral de los alumnos.

La primera tendencia la podríamos catalogar como reactiva en la medida que supone una reacción del profesor en forma de llamada de atención o castigo ante el comportamiento disruptivo de los alumnos. La intervención se produce para corregir o sancionar el comportamiento de aquellos alumnos que han trasgredido las normas. Es una estrategia de tipo represivo que trata de que los alumnos cumplan las normas para

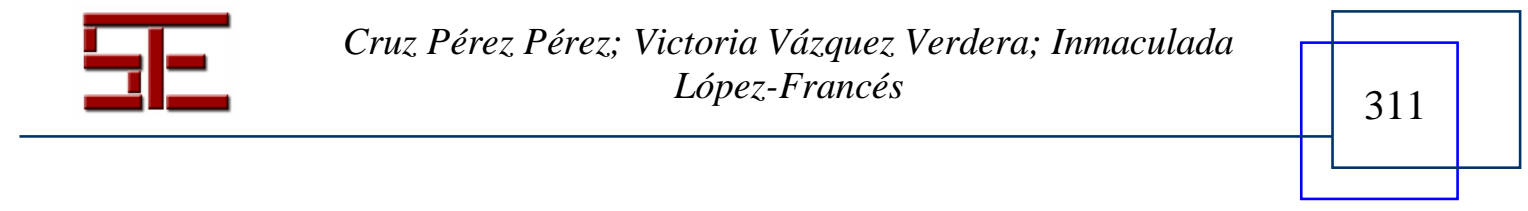




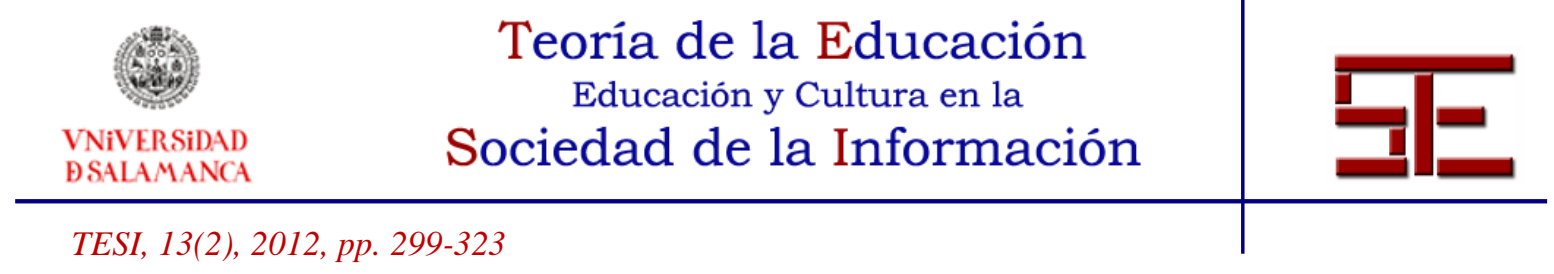

evitar la bronca o el castigo del profesor; pero también se puede considerar como una tendencia, común en muchos profesores, a reaccionar de un modo impulsivo ante la conducta de los alumnos, más que conforme a unos patrones reflexivos de intervención. En este modelo reactivo, los alumnos entran en contacto con las normas a través de las sanciones asociadas. Por ello no suelen tener los puntos de referencia claros y el docente, al no basar su intervención en un sistema normativo concreto, suele caer en la arbitrariedad al aplicar los castigos. Así, por ejemplo, es frecuente en estos casos que se llame la atención a un alumno que está hablando con su compañero y se deje pasar el mismo comportamiento en otro alumno; o que se sancione la conducta de un alumno ocurrida en un momento concreto y se deje de sancionar cuando ocurre en otro momento. Estas situaciones hacen que impere en el aula una sensación de arbitrariedad e injusticia por parte de la autoridad, y generan menos oportunidades para interiorizar las normas y las expectativas sociales.

Una segunda actitud que podríamos denominar preventiva es aquella en la que el profesor pone el énfasis en el comportamiento correcto haciendo referencia de modo continuo al mismo. El profesor explica las normas existentes, razona y justifica la bondad de las mismas, e incluso premia y estimula el comportamiento respetuoso con las normas, dejando las sanciones como algo más esporádico y secundario. De este modo es más fácil que los alumnos asuman las normas como algo bueno y necesario para la convivencia de todo el grupo y, por lo tanto, las integren como punto de referencia de su comportamiento.

Aunque entre ambas formas de actuar se dan todas las variables intermedias posibles, no cabe duda de que el valor educativo de los planteamientos preventivos es mucho mayor que el de los reactivos, y ello es así porque el primero está asociado a valores, facilitando el paso de la heteronomía a la autonomía moral de los alumnos (Piaget, 1932). Cuando el profesor especifica el comportamiento correcto de forma clara e inequívoca, está aportando a los alumnos los puntos de referencia necesarios para guiar su conducta. De este modo, las normas están presentes de un modo anticipado y continuo, y sirven a los alumnos de punto de referencia para saber lo que se espera de ellos en el contexto escolar. Es un proceso que facilita la interiorización del sistema normativo por parte de los alumnos.

En este sentido es interesante comentar los resultados de una investigación llevada a cabo por las profesoras Fierro y Carvajal (2003) sobre las "vías en que se hacen presentes las normas en la vida escolar”. Estas profesoras realizaron una observación

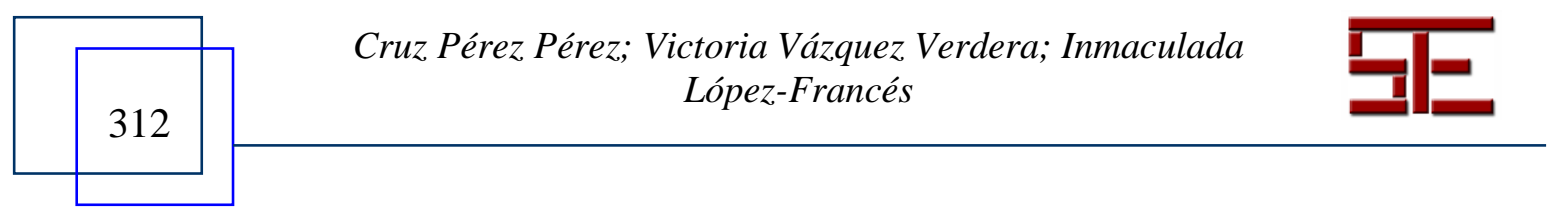




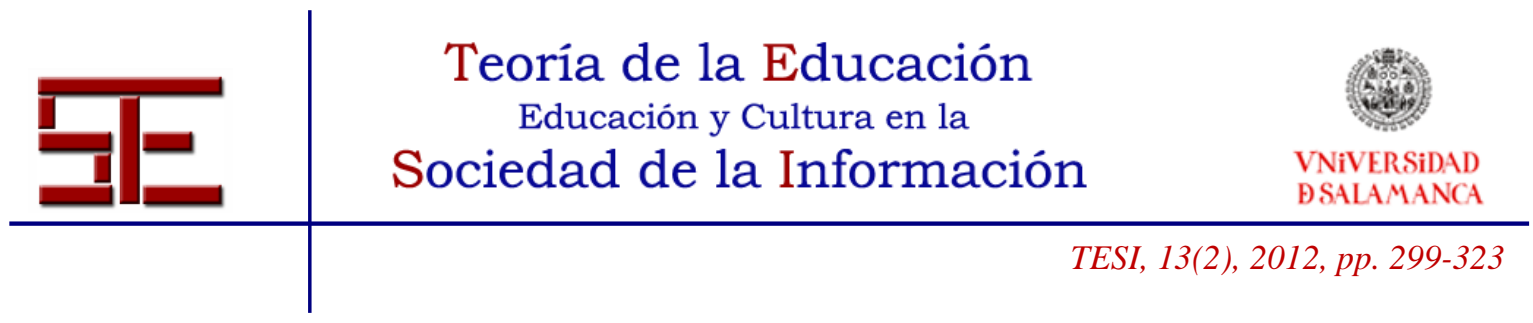

sistemática en varios centros de E. Primaria de México, e identificaron 1306 alusiones de los docentes a distintas normas concretas, bien como reacción a la transgresión de las normas, o bien como indicación preventiva. Es muy significativo que el $86 \%$ del total se corresponda con este segundo modelo, y solamente el $14 \%$ con el primero. Resultados similares fueron observados en nuestro país en una investigación sobre el tema realizada por uno de los autores de este trabajo (Pérez, 1996).

Esta desproporción entre el uso del modelo preventivo (alusiones por indicación preventiva) y del modelo reactivo (alusiones por llamadas de atención) indica que los docentes afrontan el tema de la conducta de los alumnos en forma de "reacción" ante los comportamientos considerados inadecuados, más que dirigiendo su atención hacia la exhortación o la indicación sobre la importancia y la necesidad de cumplir las normas establecidas. Por otra parte, el elevado porcentaje de alusiones reactivas al cumplimiento de normas, mediante llamadas de atención ante su transgresión, pone de manifiesto el enorme esfuerzo que realizan los docentes para controlar el comportamiento de los alumnos.

La necesidad, cada vez mayor, que tiene el profesorado de atender a las continuas situaciones problemáticas que se presentan en su quehacer diario en el aula les lleva a mantener un comportamiento reactivo desproporcionado. Esta actitud, lejos de mejorar la situación, acaba agravándola en la medida que los alumnos no interiorizan las normas y sólo las cumplen ante la presión de la autoridad. Por ello supone una gran tensión y desgaste para el profesorado que ve como cuando "baja la guardia" aumenta en gran medida la conflictividad en el aula.

Mejorar esta situación implica pasar de un modelo básicamente reactivo en el que el profesor lo basa todo en la figura de su autoridad, que es la que propone, regula, interpreta las normas y aplica las sanciones según su criterio, a un modelo preventivo, en el que se delega una parte de la tarea en los propios alumnos y en la organización de un sistema de control. En la medida que seamos capaces de equilibrar ambos tipos de intervención, aportaremos más claridad al alumno sobre lo que se espera de él en función de las normas establecidas, y ello redundará en una mayor y mejor interiorización de las mismas.

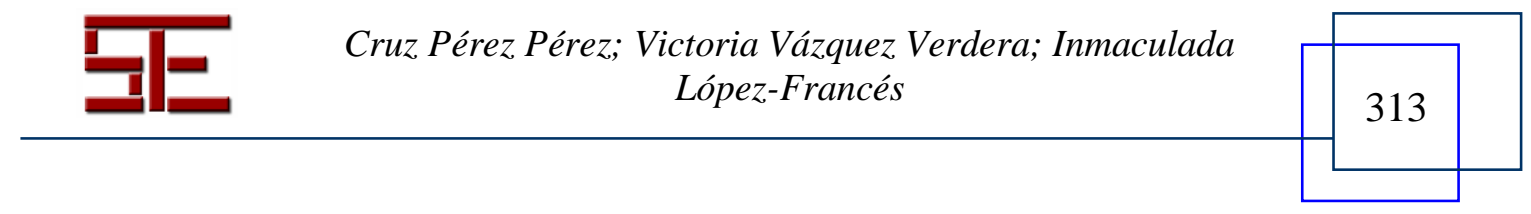




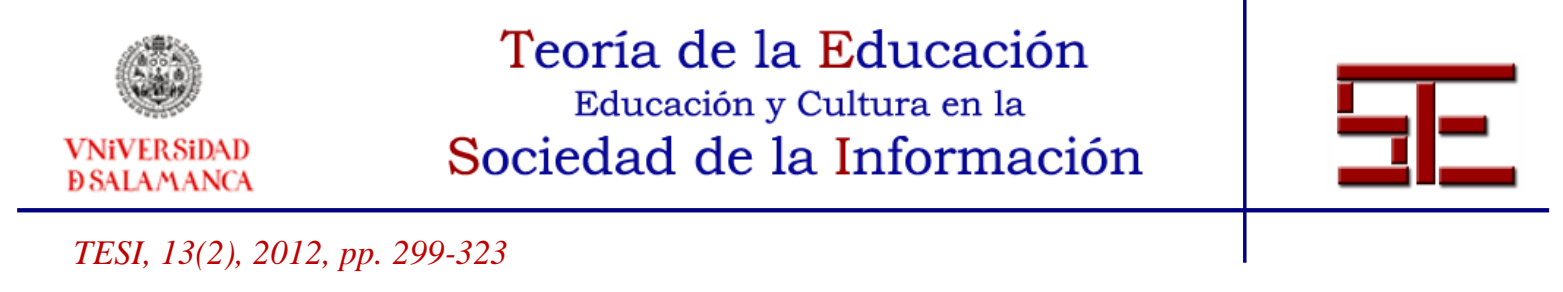

\section{5.- Modelos de intervención educativa: ¿quién debe poner las normas del aula?}

A la hora de contestar a esta cuestión, podemos observar que existen dos modelos claros establecidos: el autoritario y el participativo, con todas las variables intermedias posibles.

\subsection{1.- El modelo autoritario}

Se caracteriza por estar centrado en la autoridad del profesor que es quien propone las normas, regula las condiciones de aplicación, plantea las excepciones que considera necesarias y establece el sentido y finalidad de las mismas. El alumno se limita a acatar lo establecido por el profesor.

Tal y como se ha señalado con anterioridad, el rasgo más característico de este modelo autoritario es la orientación reactiva del comportamiento normativo docente, en el sentido de que la mayor parte de las alusiones a normas concretas se presentan como llamadas de atención, por parte de la autoridad, ante su incumplimiento por parte de los alumnos. En este modelo es frecuente que el alumno entre en contacto con el sistema de normas a través de las transgresiones que comete, las cuales suelen quedar al arbitrio del docente que decide a quién llama la atención, a quién aplica una sanción o a quién le pasa por alto una infracción.

Algunas investigaciones recientes como las mencionadas (Fierro y Carvajal, 2003; Pérez, 2007, 2009) ponen de manifiesto las dificultades de este modelo, pues los docentes se ven obligados a realizar una gran cantidad de alusiones a las principales normas mediante llamadas de atención ante su transgresión. Ello supone un gran esfuerzo y gasto de energía, para mantener el orden y controlar al grupo, que se debe realizar de forma continuada, sin que se llegue a interiorizar un modelo de comportamiento, pues en el momento en que no está presente la autoridad o la posibilidad de sanción, se incumplen las normas.

Desde la perspectiva del desarrollo moral de los alumnos, se puede considerar que este modelo es poco apropiado para conseguir que avancen desde la etapa de la socialización, basada en el respeto a las normas impuestas por la autoridad, a la etapa de la autonomía moral, basada en la interiorización y aceptación voluntaria de las normas, al comprender su necesidad para la convivencia con los iguales.

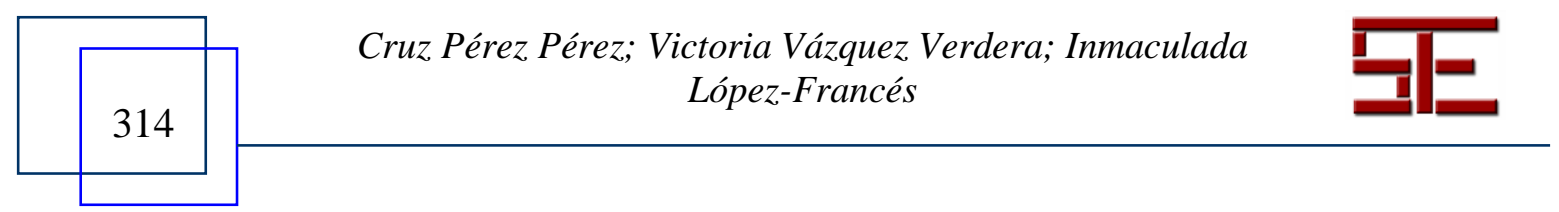




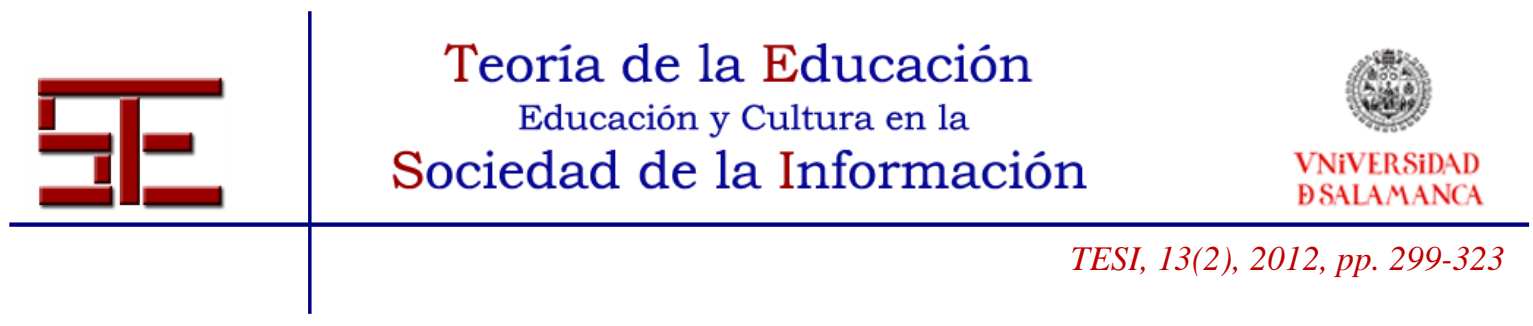

Por otra parte, cuando la regulación de la convivencia se basa mayoritariamente en la imposición de normas y sanciones de un modo autoritario, los alumnos que suelen salir más perjudicados son aquellos que se encuentran con mayor desventaja socioeducativa.

\subsection{1.- El modelo participativo}

Es aquel que permite a los alumnos participar en el gobierno del aula y del centro, de forma que ellos mismos elaboren sus normas por procedimientos democráticos, colaboren en la toma de algunas decisiones que les afectan, asuman responsabilidades, resuelvan sus conflictos de forma pacífica, tratan abiertamente los temas que les afectan, etc. Es un modelo caracterizado por la existencia de cauces estables donde ejercer el diálogo, en el que todos puedan expresar libremente sus ideas y opiniones.

Estos procesos de participación encierran en sí mismos un gran valor educativo, en la medida que permiten al alumno adquirir una experiencia real de elaboración, negociación, resolución de conflictos, búsqueda de soluciones, etc. tan necesarias para la vida diaria.

Por otra parte, el aprendizaje de normas en el aula constituye una experiencia real, muy próxima a la experiencia y los intereses de los alumnos, que permite trabajar valores como la responsabilidad, el respeto, la participación, el diálogo y la democracia. A su vez les enseña a participar en asambleas de aula, a trabajar en pequeños grupos, a formular propuestas y a llegar al consenso a través del diálogo y la negociación.

La investigación experimental en este campo ha demostrado en múltiples ocasiones que cuando el docente genera oportunidades de reflexión sobre la convivencia en el aula e involucra a sus alumnos en la misma, se produce una clara tendencia a la disminución de las conductas disruptivas en el aula (Escámez y Pérez, 1998, Fierro y Carvajal, 2003; Pérez, 2007; Pérez, 2009). Existen programas y técnicas de intervención pedagógica en este campo, objeto de constante preocupación de los docentes, que pueden mejorar de manera significativa la práctica educativa, así como de las condiciones de trabajo del profesorado y de aprendizaje de los alumnos.

Pero llegados a este punto es necesario plantearse algunas cuestiones como las siguientes: ¿Son los alumnos de la ESO capaces de organizar el comportamiento y la convivencia en el aula? ¿Están capacitados para elaborar sus propias normas? o ¿Solamente se trata de un planteamiento teórico que resulta inviable de llevar a la

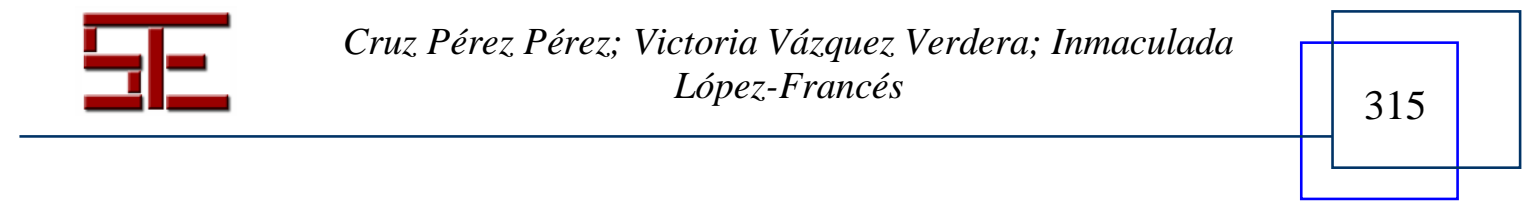




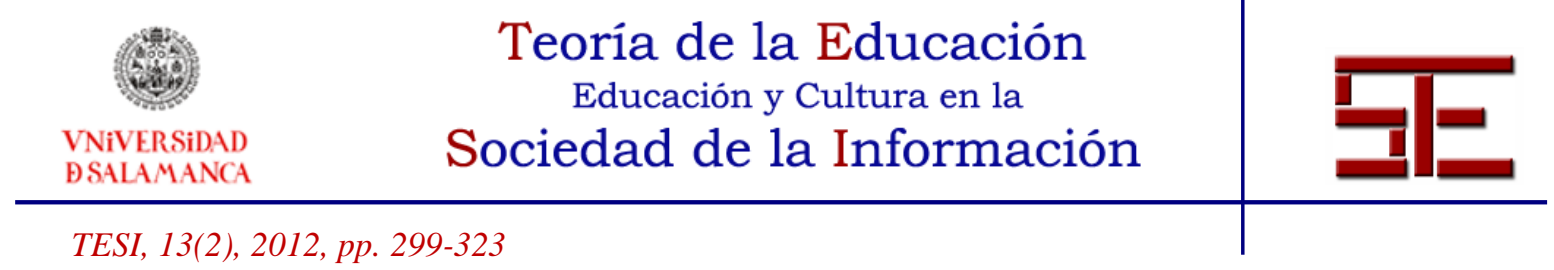

práctica? En todo caso, ¿qué nivel de responsabilidad y autonomía pueden asumir en el funcionamiento del aula?

Evidentemente cada situación y cada aula son diferentes, pero, de modo general, se puede afirmar que los alumnos, cuando se les da la oportunidad de participar en la organización de la convivencia en el aula mediante la elaboración de normas y el cumplimiento de responsabilidades, responden muy bien a la confianza que se les otorga y son capaces de hacerlo de un modo responsable y coherente, proponiendo normas y consecuencias lógicas y razonables, que no se alejan en gran medida de las que propondría el profesorado (en muchos casos las sanciones son más rígidas). Cuando se utilizan procedimientos democráticos de participación y toma de decisiones y es la mayoría de la clase la que tiene que decidir, las posturas más radicales no prosperan. El proceso, como es lógico, está influenciado por el profesor-tutor que, aunque actúa como un miembro más, utiliza su capacidad para argumentar y razonar las propuestas, de tal manera que las normas que se aprueben sean viables de llevar a cabo y resulten eficaces para el gobierno de la clase.

De cualquier modo, lo más importante es que, al final del proceso, los alumnos se sientan protagonistas y autores de las normas del aula. Esto otorga a las normas una fuerza moral incuestionable que facilita su aceptación y cumplimiento por parte de los alumnos. De este modo, las normas ya no son el fruto de una imposición arbitraria del profesorado, sino que son elaboradas, negociadas y consensuadas por toda la clase.

\section{6.- Normas para poner normas}

El proceso de elaboración de las normas del aula es relativamente complejo y requiere de un entrenamiento previo de los alumnos, que pasa por la clarificación del concepto de norma, diferenciándolo del de sanción, y por el establecimiento de una serie de directrices que permitan a los alumnos elaborar unas normas adecuadas, bien redactadas y factibles de llevarse a cabo.

Definición: Las normas son pautas o reglas de conducta que determinan lo que hemos de hacer o no en unas circunstancias concretas. Ejemplo de norma de tráfico: Debemos respetar los límites de velocidad de las autopistas que está establecido en $120 \mathrm{~km} / \mathrm{h}$. Sanción: La cantidad de dinero que hemos de pagar como multa, en función del porcentaje que supere a la velocidad máxima permitida, y los puntos que perdemos en el carnet.

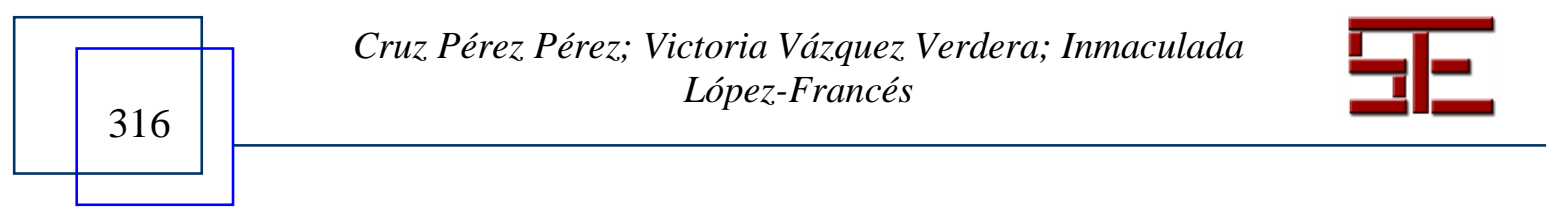




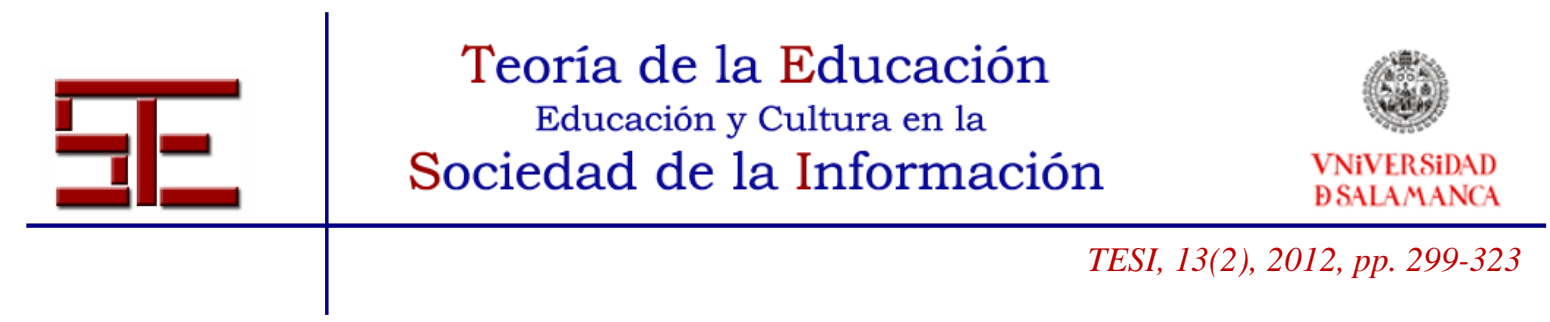

Ejemplo de norma escolar: Debemos tratar con el máximo cuidado los libros de la biblioteca de aula, evitando que se rompan o deterioren. Sanción para la norma anterior: el alumno o la alumna que trate de modo inadecuado un libro, de modo que se estropee o deteriore, deberá comprar uno nuevo.

Una vez clarificado el concepto, debemos establecer unos criterios con los que se deben establecer las normas.

a) Las normas no pueden ser muy numerosas. Debemos limitarnos a poner normas sobre aquellos aspectos de la convivencia que consideremos más necesarios. De este modo las recordaremos con más facilidad y esteremos más atentos a su cumplimiento.

b) Debemos establecer los grandes grupos o aspectos de nuestra convivencia sobre los que podemos elaborar normas más o menos homogéneas. De este modo se facilita su realización.

c) Las normas deben establecer con claridad el comportamiento correcto que pretenden fomentar. Por ello no es aconsejable formularlas como una serie de prohibiciones en sentido negativo.

d) Las normas deben ser muy claras y muy concretas de forma que todos los alumnos y profesorado puedan determinar cuándo se cumplen y cuándo no.

e) Podemos establecer normas sobre aspectos que afectan a la convivencia en nuestro centro y nuestra aula, pero estas normas no pueden ir nunca en contra de otras normas de rango superior establecidas por el Reglamento de Régimen Interno del centro, la Consejería de Educación o la propia Constitución española.

f) Las normas deben ser razonables, en el sentido de que todos los alumnos de la clase las puedan cumplir con un esfuerzo moderado. Si las normas resultan metas inalcanzables para algunos alumnos, éstas se acaban transgrediendo y generan frustración y ansiedad.

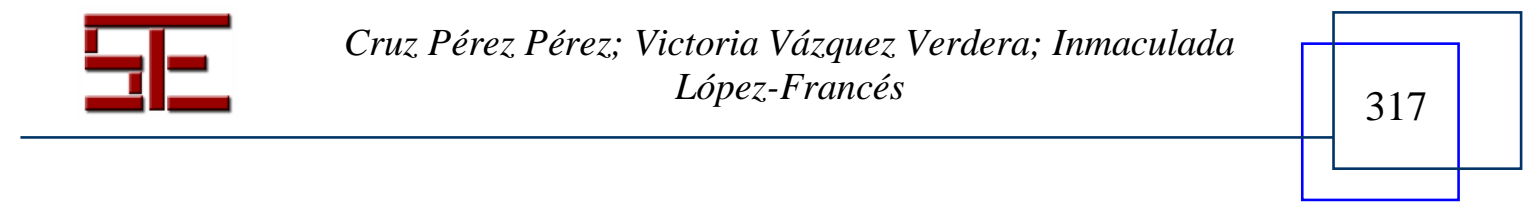




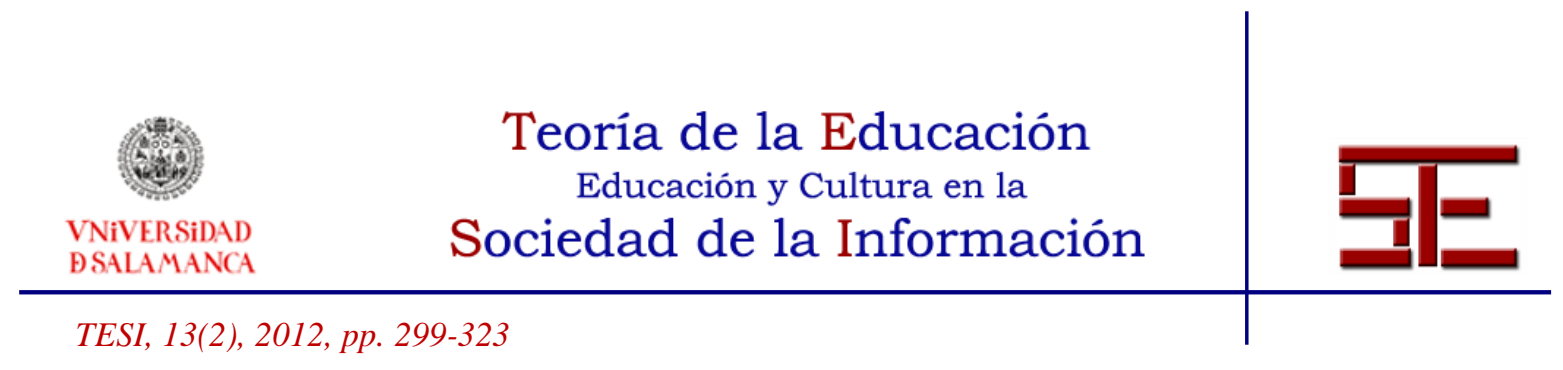

g) Las normas deben ser consensuadas por todos los alumnos y profesorado afectados por las mismas. Cuando una norma no sea aceptada por unanimidad, debe modificarse tratando de alcanzar el consenso sobre la misma.

4.6.1-Pautas para la elaboración de las sanciones

a) Igual ocurre con las sanciones o consecuencias sobre el incumplimiento de las normas. Es necesario establecer unas normas y/o directrices para su elaboración.

b) Debe establecerse al menos una consecuencia para cada norma, la cual se aplicará a las personas que no la cumplen. Cuando una norma, por muy beneficiosa que sea, no está asociada a una sanción, se acaba transgrediendo de modo sistemático.

c) Las consecuencias deben ser muy concretas de forma que todos los alumnos y profesorado puedan determinar cuándo se cumplen y cuándo no.

d) Las consecuencias por el incumplimiento de una norma deben ser proporcionales a la gravedad de la infracción cometida.

e) Las consecuencias establecidas no deben tender nunca a humillar a la persona ni, por supuesto, a causarle ningún daño físico.

f) Las sanciones, siempre que sea posible, deben estar orientadas a corregir la situación creada por el infractor de la norma, más que a penalizar su comportamiento.

g) Se deben establecer varias consecuencias, ordenadas en función de su dureza, para el incumplimiento de cada norma. No se debe sancionar del mismo modo la infracción ocasional de una norma que su reiterado incumplimiento.

\section{7.- Criterios generales para la aplicación de las normas}

1.- Las normas deben figurar de modo escrito en lugar preferente. Una vez elaboradas y aprobadas, se deben colocar en un panel que resulte visible para todos, al objeto de que se tengan presentes en todo momento y el profesorado o los propios alumnos y alumnas puedan hacer referencia a las mismas.

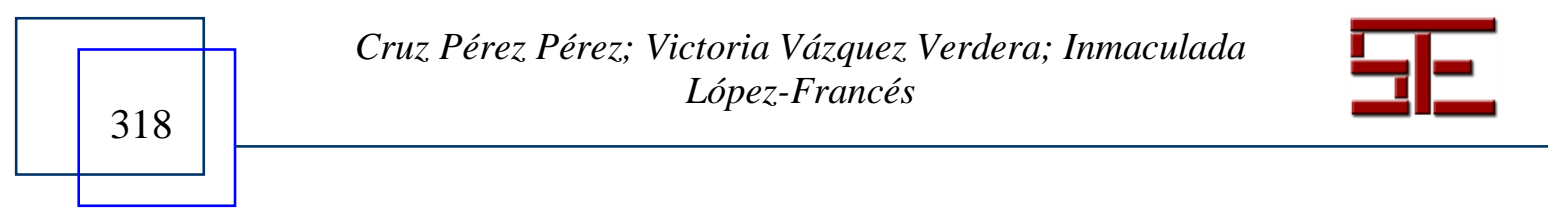




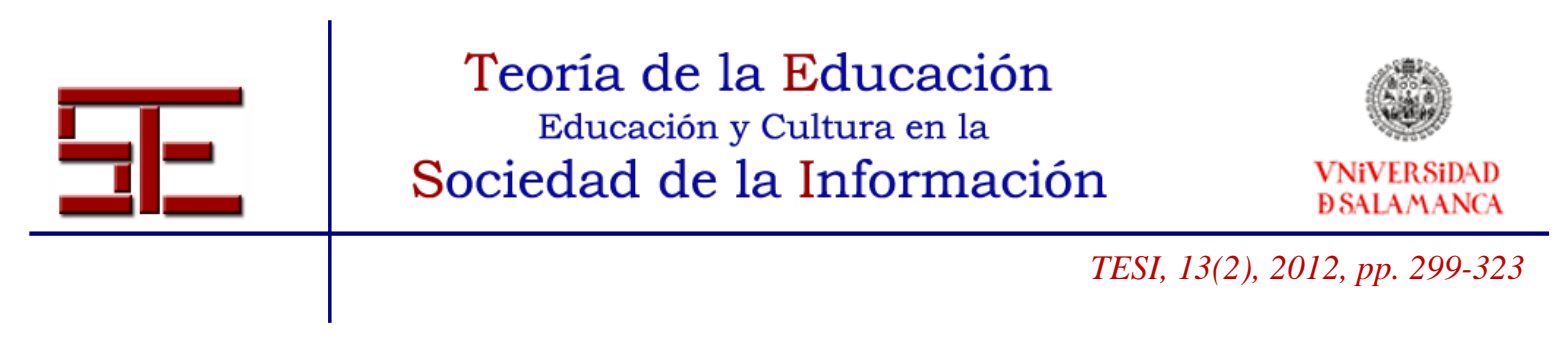

2.- El profesorado es el encargado de aplicar las sanciones establecidas cuando corresponda. Es recomendable la ejecución de la sanción, especialmente cuando se trata de anotación de faltas, del modo más neutro posible, ignorando las protestas del alumno o alumna afectado/a.

3.- Si el profesor o la profesora lo considera oportuno, y ante los comportamientos transgresores de normas menos graves, puede realizar una advertencia que permita al alumno o alumna tomar conciencia de su conducta. Pero esta advertencia es importante que se realice una sola vez, pues de lo contrario los alumnos se habituarán a las mismas y no tendrán ningún efecto.

4.- Dentro del abanico de sanciones establecidas que puede aplicar el profesorado ante un comportamiento disruptivo, deben primar las que tienden a corregir la situación creada por el infractor de la norma por encima de aquellas que penalizan la conducta para que no se vuelva a repetir.

5.- A pesar de que las normas están ahí y de que se deben aplicar del modo más claro y objetivo para todos, el profesorado tiene un margen de maniobra importante que permite adaptar su aplicación a la variedad de situaciones que se pueden producir y a la diversidad del alumnado.

6.- Es conveniente utilizar mecanismos de "amplificación". Se trata una técnica muy eficaz que permite a los alumnos y alumnas tomar conciencia de las consecuencias del incumplimiento de las normas, al observar las mismas en un compañero o compañera. Para ello el profesor o la profesora, cuando el momento es apropiado, comenta en voz alta la falta cometida por un alumno o alumna y la sanción que se le va a aplicar. También se debe aplicar en sentido positivo alabando públicamente a aquellos alumnos o alumnas que han cumplido las normas en un periodo determinado.

7.- El profesor o la profesora debe aplicar las consecuencias establecidas por no cumplir las normas del modo más inmediato posible. Retrasar innecesariamente la aplicación de la sanción aumenta la resistencia de los alumnos hacia las mismas y disminuye los efectos educativos.

8.- El profesor o la profesora debe llevar un registro sencillo pero eficaz de las sanciones establecidas. En las sanciones leves basta con anotar la "falta", pero en las

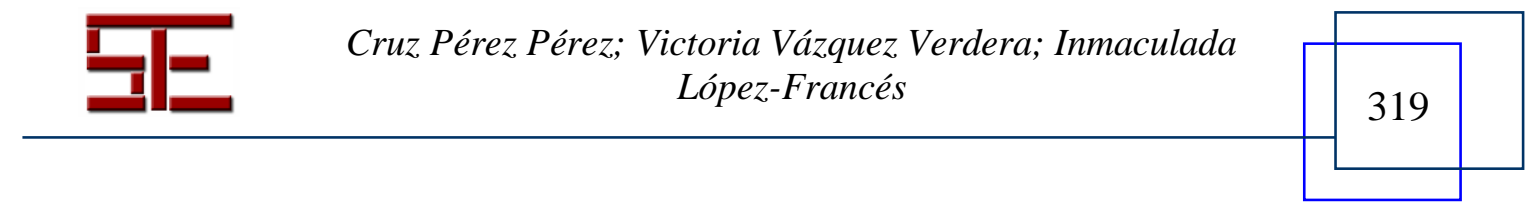




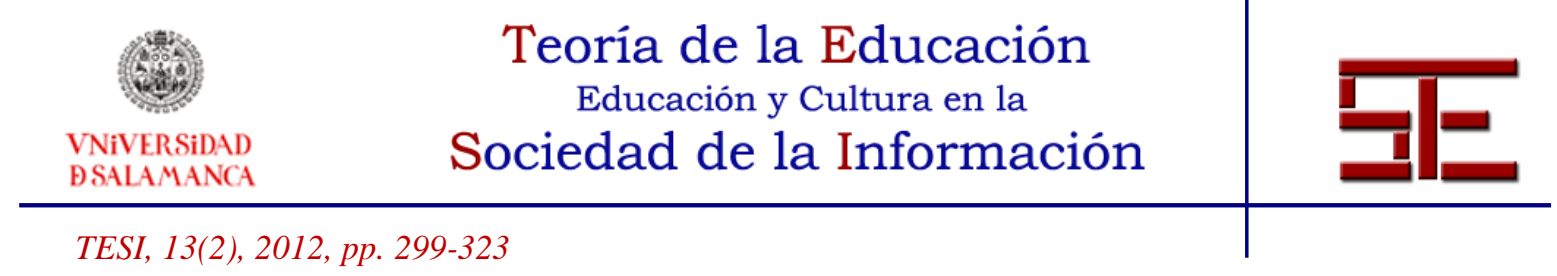

más graves se debe anotar, al menos, la fecha, el nombre del profesor o profesora que sanciona y una breve descripción de los hechos ocurridos.

9.- Deben existir mecanismos de control y seguimiento que permitan valorar la bondad y utilidad de las normas y sanciones establecidas. Estos mecanismos son las reuniones de todos los profesores que intervienen en un grupo de alumnos y las asambleas de aula, foros en los que se debe analizar el funcionamiento de las normas establecidas.

Esquema del proceso:

Criterios para la puesta en práctica de las normas
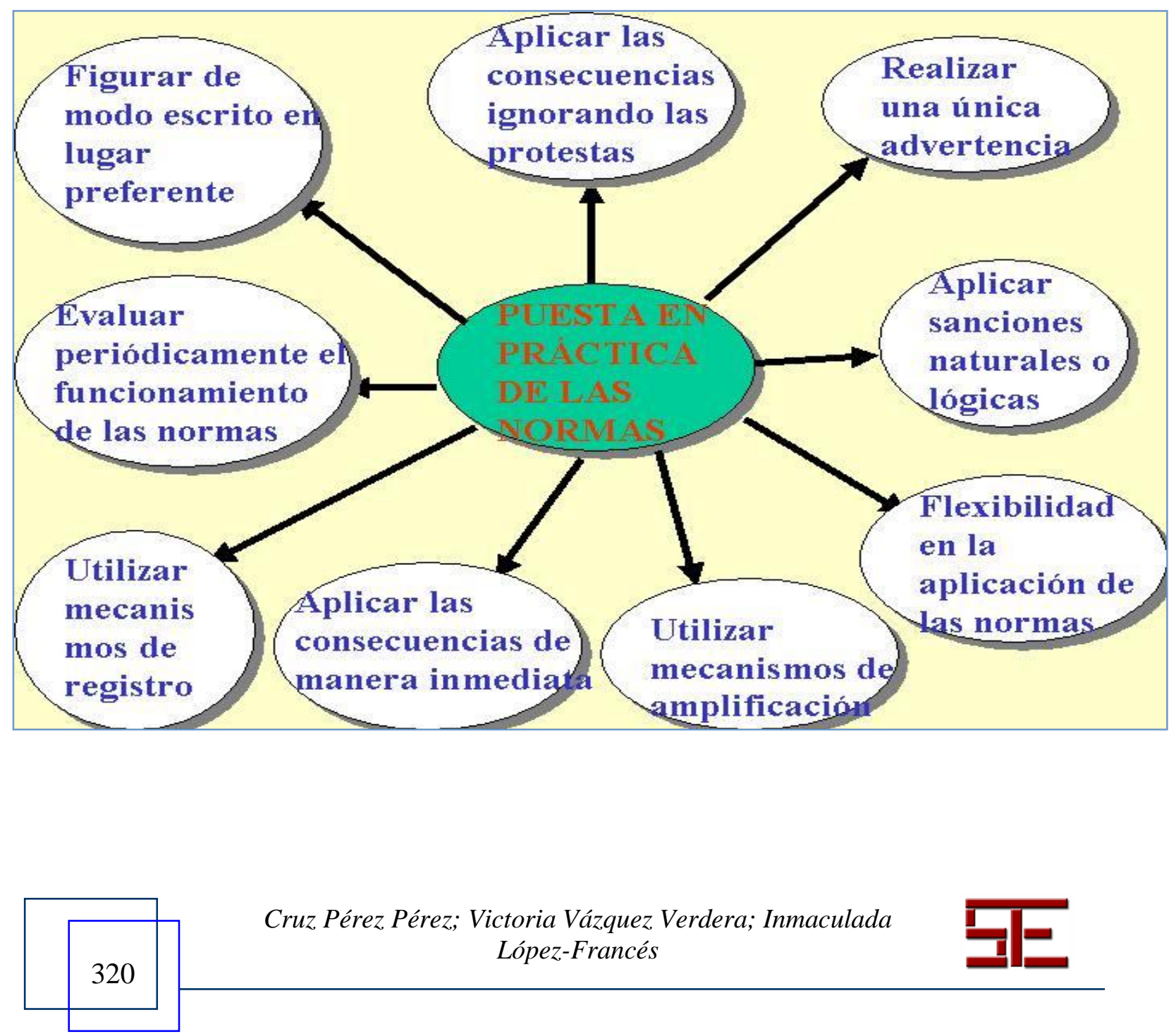


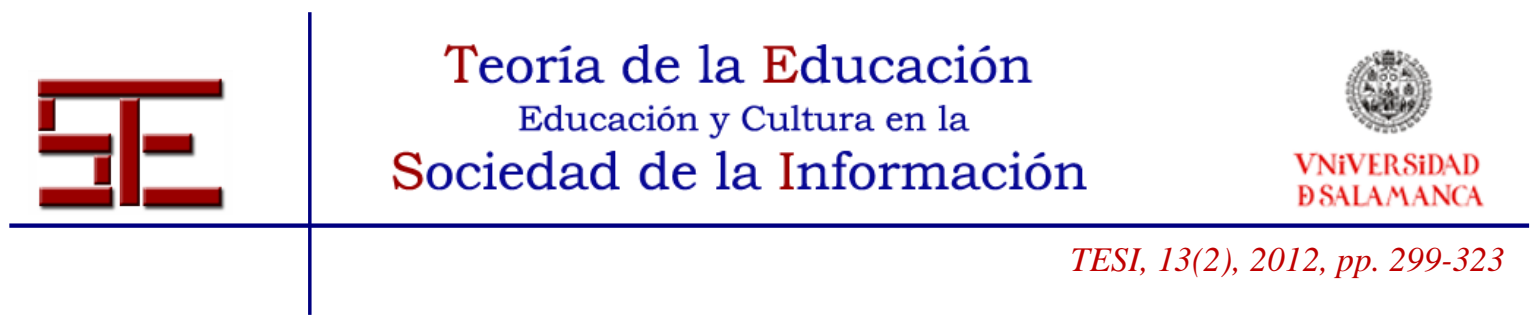

\section{5.- A MODO DE CONCLUSIÓN}

En los Institutos de Educación Secundaria es posible trabajar los valores de la autonomía y la responsabilidad del alumnado, estableciendo un modelo de aprendizaje de normas que regule las relaciones entre las personas, ayude a afrontar los conflictos de un modo constructivo y genere un clima favorable para el aprendizaje. Pero el modo como se organiza e implanta este modelo también es importante a nivel educativo. Cuando se aplican procesos participativos en los que se implica de modo responsable al alumnado, los resultados suelen ser muy satisfactorios y se produce una mejora significativa del clima de convivencia. Por el contrario, cuando se ignoran las opiniones de los alumnos en aquellos asuntos que les incumben, se puede provocar una "indefensión aprendida", en el sentido de que éstos perciben que no existe relación entre su comportamiento y los cambios que se pueden producir en el entorno, pues son los profesores, los padres o los políticos los que tienen el poder para modificar las cosas e influir sobre el futuro. Por ello es importante los alumnos se sientan protagonistas y autores del modelo de convivencia del aula. Unas pautas de convivencia que hayan sido elaboradas, negociadas y consensuadas por toda la clase se alejan del modelo impositivo $\mathrm{y}$ autoritario, lo cual les otorga una fuerza moral incuestionable que facilita su aceptación y cumplimiento.

En consecuencia, según estos planteamientos, los auténticos factores de aprendizaje de valores como la autonomía y la responsabilidad en situaciones de diversidad cultural son los que los alumnos y alumnas aprenden a través de su participación en el medio escolar, familiar y social, muy por encima de los contenidos informativos y conceptuales sobre valores que se enseñan en el medio escolar o de los mensajes verbales del profesorado. Estas intervenciones, con ser necesarias no son suficientes ni decisivas en la enseñanza de valores. Por ello la educación en valores debe suponer un aprendizaje práctico, realizado en la cotidianidad de la vida del alumnado, que permita la construcción de una forma de ser, de pensar y de relacionarse con los demás y con el medio que le rodea según criterios de felicidad personal, pero también de solidaridad, de búsqueda del bien común.

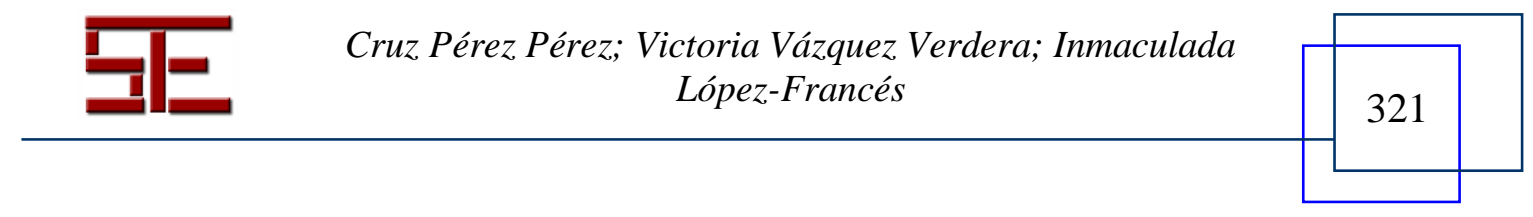




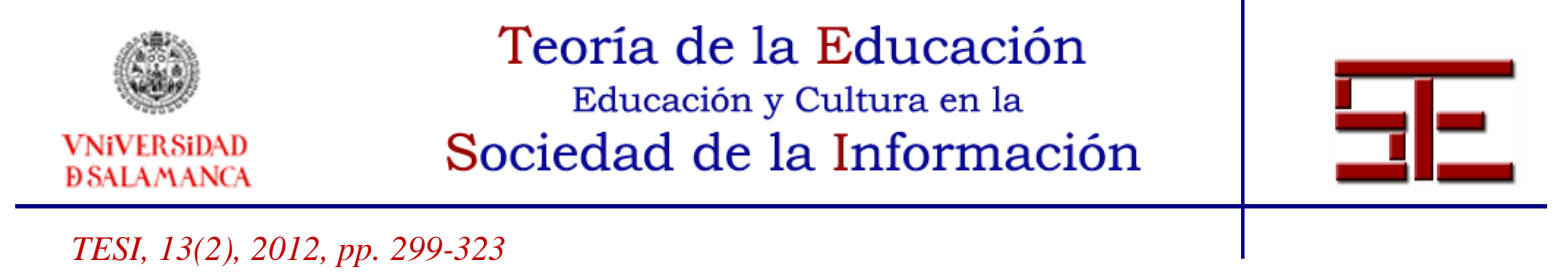

\section{6.- BIBLIOGRAFÍA}

Cortina, A. (1996). Educar moralmente. ¿Qué valores para qué sociedad? En Cortina y otros (Eds.), Un mundo de valores (pp. 27- 37 ). Valencia: Generalitat Valenciana.

Fierro, M. y Carvajal, P. (2003). Mirar la práctica docente desde los valores. México: Gedisa.

Martínez, M. (1998). El contrato moral del profesorado. Bilbao: Desclée De Brouwer.

Ortega, P., Mínguez, R. \& Gil, R. (1996). Valores y educación. Barcelona: Ariel.

Pérez, C. (1996). Las normas en el currículum escolar. Técnicas para el aprendizaje de normas en el aula mediante la participación democrática. Madrid: E.O.S.

- (2007). Efectos de la aplicación de un programa de educación para la convivencia sobre el clima social del aula en un curso de $2^{\circ}$ de E.S.O. Revista de Educación del Ministerio de Educación y Ciencia, 343.

- (2009). Valores y normas para la convivencia en el aula. Madrid. EOS.

Pérez, C. y Asensi, C. (2000). Educación para la convivencia: programa de intervención para Educación Primaria. Aula de Innovación Educativa, 93-94.

Pérez, C. y Llopis, A. (2003). El profesor ente la educación en valores y actitudes. Bordón, 55, 4, 541-553.

Pérez, C. y López-Francés, I. (2010). Educar para la convivencia en los centros escolares. Edetania, 38, 73- 94.

Piaget, J. (1932). The moral judgment of the child. Londres: Routledge y KeganPaul.

Zubiri, X. (1992). Sobre el sentimiento y la volición. Madrid: Alianza Editorial.

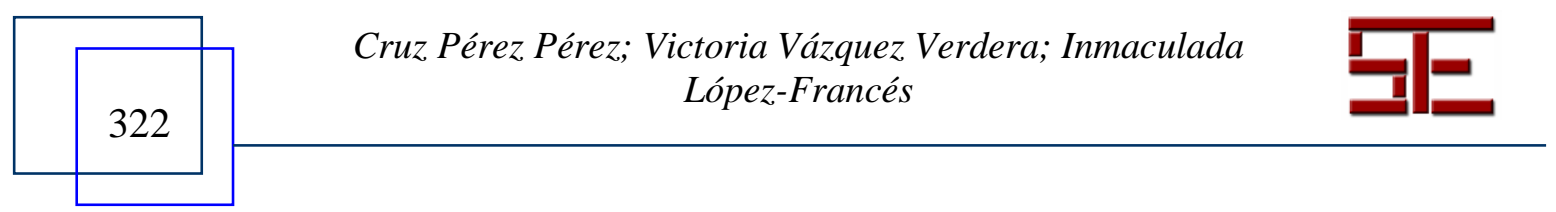




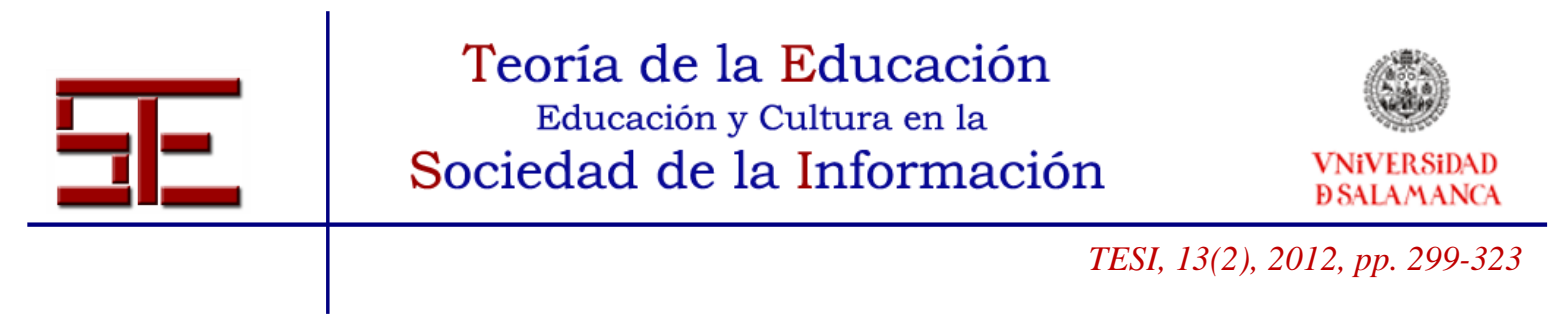

Para citar el presente artículo puede utilizar la siguiente referencia:

Pérez Pérez, C., Vázquez Verdera, V. y López-Francés, I. (2012). Autonomía y responsabilidad como valores clave para la elaboración de normas de convivencia en la ESO. Revista Teoría de la Educación: Educación y Cultura en la Sociedad de la Información. 13(2), 299-322 [Fecha de consulta: dd/mm/aaaa].

http://campus.usal.es/ revistas_trabajo/index.php/revistatesi/article/view/9010/9254

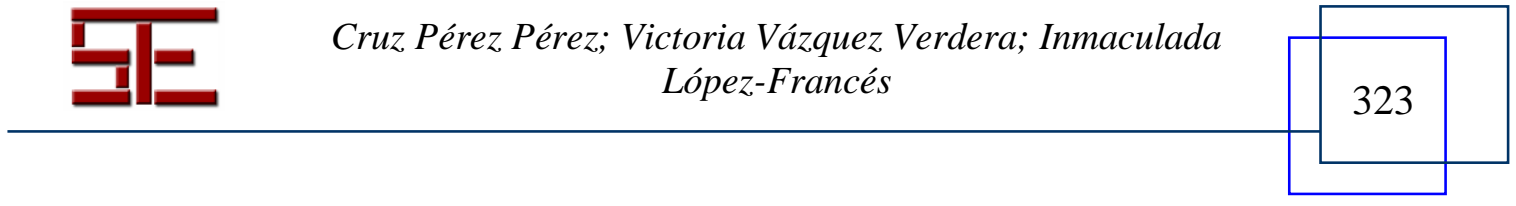

